\title{
The toolbox of porous anodic aluminum oxide-based nanocomposites: from preparation to application
}

\author{
Xia Huang ${ }^{1,2} \cdot$ Hatice Mutlu ${ }^{2} \cdot$ Patrick Théato ${ }^{1,2}$ \\ Received: 3 June 2020 / Revised: 14 August 2020 / Accepted: 19 August 2020 / Published online: 25 September 2020 \\ (C) The Author(s) 2020
}

\begin{abstract}
Anodic aluminum oxide (AAO) templates have been intensively investigated during the past decades and have meanwhile been widely applied through both sacrificial and non-sacrificial pathways. In numerous non-sacrificial applications, the AAO membrane is maintained as part of the obtained composite materials; hence, the template structure and topography determine to a great extent the potential applications. Through-hole isotropic AAO features nanochannels that promote transfer of matter, while anisotropic AAO with barrier layer exhibits nanocavities suitable as independent and homogenous containers. By combining the two kinds of AAO membranes with diverse organic and inorganic materials through physical interactions or chemical bonds, AAO composites are designed and applied in versatile fields such as catalysis, drug release platform, separation membrane, optical appliances, sensors, cell culture, energy, and electronic devices. Therefore, within this review, a perspective on exhilarating prospect for complementary advancement on AAO composites both in preparation and application is provided.
\end{abstract}

Keywords Anodic aluminum oxide $\cdot$ Non-sacrificial $\cdot$ Isotropic $\cdot$ Anisotropic $\cdot$ Nanocomposites

\section{Introduction}

Combinations of different materials are often applied to design composites with particular use that is not inconceivable by the individual parts. Nanocomposites involved with nanoscale dimensions or bearing nanometer-scale structures found wide applications in science and technology [1-3]. Porous templates, such as ion track etched membranes, anodic metal oxides, porous silicon, and block copolymer templates, can not only be used for sacrificial nano-patterning but also capable to be fabricated into nanocomposites for applications such as efficient nano-filtration, separation, storage, etc [4-6]. Among these templates, porous anodic aluminum oxide (AAO) stands out because it is characterized with self-organized cylindrical

Patrick Théato

patrick.theato@kit.edu

1 Institute for Chemical Technology and Polymer Chemistry (ITCP), Karlsruhe Institute of Technology (KIT), Engesserstr.18,

D-76131 Karlsruhe, Germany

2 Soft Matter Synthesis Laboratory, Institute for Biological Interfaces III (IBG 3), Karlsruhe Institute of Technology (KIT),

Hermann-von-Helmholtz-Platz 1,

D-76344 Eggenstein-Leopoldshafen, Germany alumina pores obtained from electrochemical oxidation and is recognized as cost effective fundamental substance for constructing functional nanocomposites [7]. The fabrication of AAOs is comprehensively studied and reviewed during the past decades [8-10], to which we aid the readers' attention. Literature survey reveals that AAO templates represent high flexibility in template thickness (i.e., pore length), pore diameter and interpore distance, which in turn enables the fabrication of nanomaterials with various dimensions. For instance, the range for pore diameter of AAOs can be attained from 6 to $400 \mathrm{~nm}$, while pore densities reach up to $10^{11} \mathrm{~cm}^{-2}$, and additionally, the pore length as long as $100 \mu \mathrm{m}$ is obtainable [11-13]. Moreover, the pores are distributed in a strict wellarranged manner that guarantees well-ordered structures of obtained nanomaterials. AAO membranes have excellent thermal stability and outstanding resistance toward organic chemicals that allow them to be applied as patterning templates for materials of both organic and inorganic nature [14-20]. In addition, high pore density and aspect ratio endow AAO membranes with a large surface-to-volume ratio. The pore walls are accessible for further functionalization that enabled AAO membranes as fundamental materials for preparing diverse nanocomposites [21, 22]. On the other hand, nanocomposites are commonly characterized by anisotropic structure, and clustering of dispersed filler may significantly affect their properties 
[23]. Therefore, the modification involves manipulating of AAO membrane surface, pore chemistry, topography, surface roughness, surface charge, surface energy, and wettability and is of particular importance to meet the demand of preparing AAO-based nanocomposites that present novel chemical and physical properties as well as morphological and interfacial characteristics for manifold applications.

Herein, we review the recent research progress on preparation techniques applicable for fabrication of AAO-based nanocomposites. Additionally, grounded on two major types of AAO membranes, isotropic through-hole and anisotropic single open-end AAO nanocomposite implemented in disparate fields are further discussed. Finally, we conclude with a perspective outlook of AAO nanocomposites over preparation to application in nanotechnologies.

\section{Methods for preparation of AAO nanocomposites}

AAO membranes provide the opportunities for functionalizing via numerous modification approaches to result in welldesigned architectures for practical usages. To date, in order to harness the distinctive properties of AAO templates, AAObased nanocomposites have been successfully prepared by combining AAO with various materials including small molecules, organic crystals, polymers, and inorganic nanostructures, by means of self-assembly, polymer grafting, coating, and template wetting strategies. Combinations of modification methodologies adjust the materials with enhanced final functionalities of obtained AAO composites. The methods mentioned under this specific subchapter are depicted in Table 1.

\section{Self-assembly}

Self-assembly technique is a commonly employed method for constructing well-defined supramolecular nanostructures [52]. Generally, self-assembly strategy consists of self-assembled monolayer (SAM) and layer-by-layer assemblies which refers to topographic functionalization. During a typical SAM formation, organic molecules assemble spontaneously by adsorbing on a surface [10]. On this account, SAMs are the most forthright approach for AAO membrane surface functionalization. AAO membranes offer potential for surface functionalization through reacting with surface hydroxyl groups as immobilization points for arrangement of monolayers [53]. Among the existing methods, silanization is the simplest and most effective SAM method to adjust membrane surface properties. Indeed, organosilanes of $\mathrm{RSiX}_{3}$-type $\left(\mathrm{X}=\mathrm{Cl}, \mathrm{OCH}_{3}\right)$ can rapidly form covalent linkages between the membrane surface and the $\mathrm{X}$-groups, which usually stabilizes the monolayer and allows further chemical modifications. During a conventional silanization process the $\mathrm{RSiX}_{3}{ }^{-}$ type silanes are either first hydrolyzed into hydroxysilanes that are capable to be adsorbed onto the AAO surface, or the surface hydroxy groups directly react with the silanes forming a stable covalent bond. Further, comprehensive lateral arrangements are taking place resulting in stable surface-crosslinked monolayers that are covalently attached on the AAO surface [54]. For instance, Szczepanski et al. had demonstrated the stability of silanes on alumina porous membrane via typical SAM processing [55].

Additionally, self-assembly silanization can also be processed during template fabrication for constructing complicated hierarchical membranes. Jani et al. [56] had described a facile method to prepare AAO membranes with

Table 1 Some methods for the preparation of AAO-based composites

\begin{tabular}{|c|c|c|c|c|}
\hline Strategy & Detailed methodology & Materials & Remarks & Refs. \\
\hline \multirow[t]{2}{*}{ Wetting } & Melt wetting & Polymer/polymer blends & Melt wetting with precursor film & [24] \\
\hline & Solution wetting & Polymer solution & $\begin{array}{l}\text { Type of solvent and concentration } \\
\text { of solution vary shape morphology }\end{array}$ & {$[25]$} \\
\hline \multirow[t]{2}{*}{ Polymer grafting } & Grafting from & Monomers and reactants & $\begin{array}{l}\text { Polymerization initiated from } \\
\text { substrate; SI-ATRP, SI-RAFT, SI-ROMP }\end{array}$ & {$[26,27,28-30]$} \\
\hline & Grafting to & Functional polymer & Coupled with pre-synthesized polymer & {$[31,32,33,34,35]$} \\
\hline \multirow[t]{2}{*}{ Self-assembly } & Layer-by-layer deposition & Charged polyions & $\begin{array}{l}\text { Multi-layer build-up via multiple } \\
\text { attractive forces }\end{array}$ & {$[33,36,37]$} \\
\hline & Self-assembled monolayer & Organosilanes & Covalent -Si-O-Si- bond & {$[38-41]$} \\
\hline \multirow[t]{4}{*}{ Coating } & Plasma-enhanced deposition & Reactants/precursor & Plasma-enhanced reaction deposition & {$[42-45]$} \\
\hline & Atomic layer deposition & & Atomic layer control & {$[46,47]$} \\
\hline & Chemical vapor deposition & & Vacuum deposition & {$[48]$} \\
\hline & Electrochemical deposition & Conductive materials & Simplex and complex deposition & [49-51] \\
\hline
\end{tabular}


a varying surface chemistry as illustrated in Fig. 1. In detail, after the first anodization step, part of the oxidized layer was removed and the remaining barrier layer was then functionalized with 3-aminopropyltriethoxysilane as the first silane layer. Starting from this first silanized layer, a second anodization step was further accomplished and the freshly generated AAO pore surface was then covered with pentafluorophenyldimethylchlorosilane derivative. Consequently, an AAO membrane that is displaying sharp a contrast in wettability within each pore was obtained. Notably, according to this strategy more surface variations could be achieved in one template via further continuous anodization and silanization steps, in which three kinds of silanes were sequentially deposited inside the AAO membrane, enhancing the surface characteristics of AAO by making the membrane chemically robust [57]. Besides silanes, also phosphonates [58], carboxylates [59], catechols [60], and alkenes/alkynes [61], are widely utilized to modify AAO membranes by forming covalently attached and densely packed organic monolayers on the pore walls.

Layer-by-layer assembly of polymer materials within the cylindrical pores of AAO membrane is also a commonly used method for membrane functionalization. The formation principle underneath is based on multiple intermolecular interactions, such as electrostatic contacts, hydrogen bonding and hydrophobic interactions [62]. For example, AAO functionalization could be achieved by choosing appropriate polyelectrolytes, such as poly(ethyleneimine) (PEI), poly(allylamine) (PAH), poly(diallyldimethylammonium chloride) (PDADMAC), poly(styrenesulfonate) (PSS), poly(vinylsulfate) (PVS), and poly(acrylic acid) (PAA), forming electrostatic layer-by-layer assembly [63]. As an

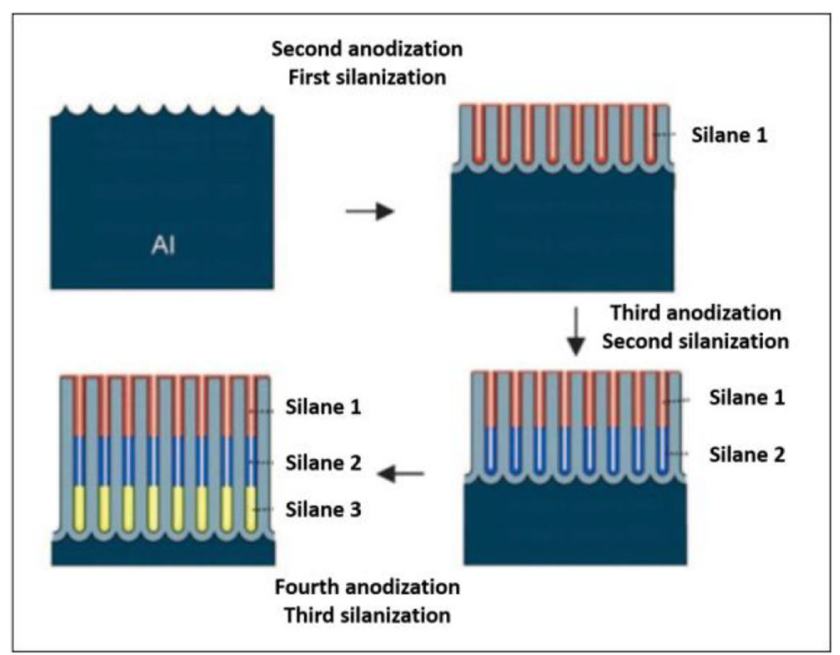

Fig. 1 Schematic stepwise diagram for the preparation of layered silanes in AAO membrane. Reprinted with permission from ref. [57]. Copyright 2010 Wiley illustration, Li and colleagues [64] have synthesized nanotubes in AAO by alternatively pressurized injection of negatively charged poly(sulfonated styrene) (PSS) polyelectrolyte and positively charged poly(allylamine hydrochloride) (PAH) polyelectrolyte solution into membrane nanopores. Upon electrostatic adsorption, layer-by-layer deposition was accomplished, and multilayers of polyelectrolytes were formed on the inner walls of the membrane. The electrostatic interactions between layers also allow entrapping of biomolecules and/or nanoparticles into assembled nanotubes, and enable the obtained AAO composites to be applied as biosensors and catalytic membranes [59].

\section{Polymer grafting}

Grafting of synthetic polymers could endow AAO membranes with a variety of functionalities and surface topographies that are strongly correlated to potential applications. Furthermore, the grafted polymers lead to membrane kaleidoscopic properties by altering parameters such as degree of polymerization, dispersity, grafting density, and distributions along the membrane pores [65]. Generally, polymer grafting methods can be categorized as "grafting to" and "grafting from" strategies. The "grafting to" polymerization relies on an anchor point on the surface of an AAO membrane that is coupled with functional groups from pre-synthesized polymers, either form reactive end-groups or reactive side-groups. Kim et al. had employed a one-step "grafting to" approach to enable an AAO membrane functionalization with polymers [31]. Correspondingly, poly( $N$-isopropylamine) (PNIPAm) was synthesized through typical reversible addition-fragmentation transfer (RAFT) polymerization and then a catechol moiety was coupled with polymer chain end-group resulting in a catechol terminated PNIPAm chain. Through high binding affinity of catechol groups to aluminum oxide, catechol modified PNIPAm brushes were tethered to the surface of AAO, as shown in Fig. 2.

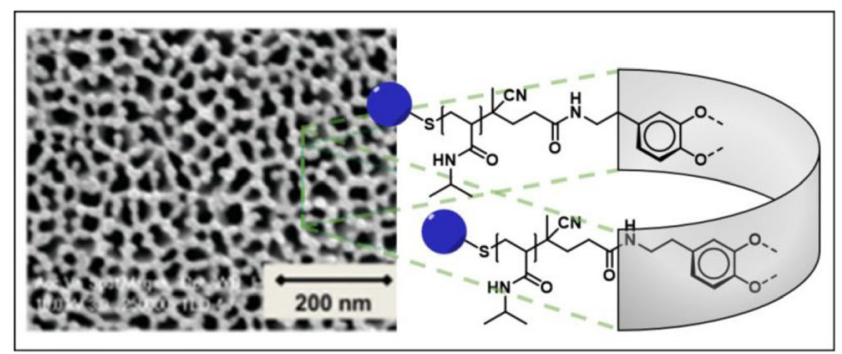

Fig. 2 Schematic illustration of catechol-PNIPAm grafted AAO composite. Reprinted with permission from ref. [31]. Copyright 2012 Royal Society of Chemistry 
Besides, two-step "grafting to" modification methods have been proposed and extensively utilized. Generally, functional anchor groups were firstly grafted onto membrane walls that allow for further stabilized immobilization of pre-synthesized polymer chains. For instance, 3glycidoxypropyl trimethoxysilane was introduced onto AAO surface to endow the membrane with reactive epoxy groups, which have been employed as reactive sites to graft polymers via a nucleophilic ring-opening reaction of the epoxides [66]. For example, PAA brushes could be grafted onto an AAO membrane through conjugation between epoxy groups and carboxyl groups, which resulted in PAA modified AAO that exhibits rapid and reversible response to external $\mathrm{pH}$ variations [32]. In addition, the group of $\mathrm{Lu}$ [33] had reported a "grafting to" method via quaternization reaction of the pyridine nitrogen atoms of poly(styrene)-block-poly(4-vinylpyridine) polymers with the bromide group from pre-modified AAO membrane as schematically illustrated in Fig. 3. Owing to the $\mathrm{pH}$ responsive characteristic of poly(4-vinylpyridine) block, the wettability of modified membrane could be changed via protonation and de-protonation of 4 vinylpyridine groups upon $\mathrm{pH}$ stimulation, which resulted in membrane reversible affinity towards oil and water, respectively. Such a smart membrane has potential to be utilized for oil/water emulsion separation and sewage purification.

Next, in a "grafting from" approach, polymer chains are grown from an initiating site on the AAO membrane surface. Generally, immobilization of initiating site onto AAO membranes is the first crucial step for a successful polymer "grafting from" methodology. Owing to the variation of synthetic approaches, a variety of "grafting from" synthesis

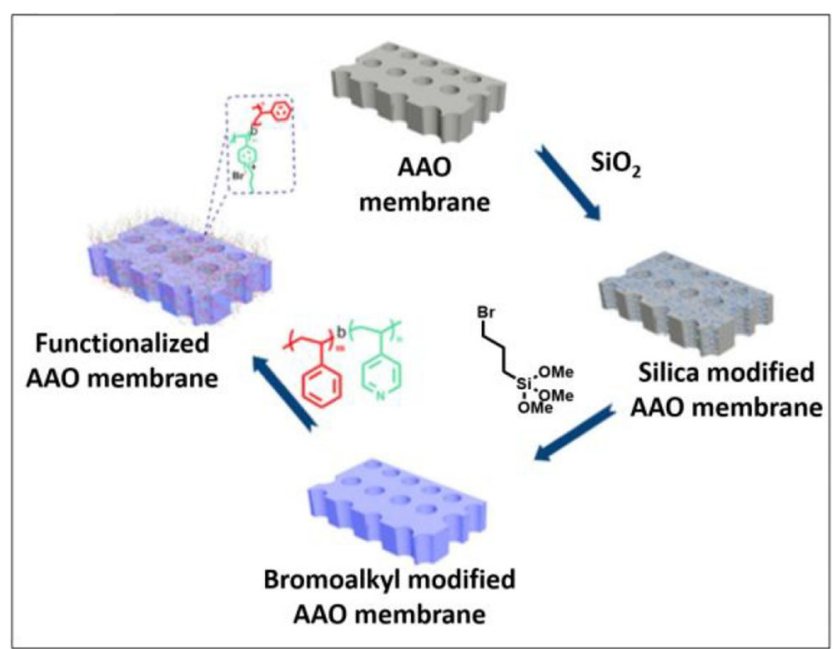

Fig. 3 Schematic illustrating of grafting to strategy for preparing poly(styrene)-block-poly(4-vinylpyridine)/AAO composites. Reprinted with permission from ref. [33]. Copyright 2018 Elsevier strategies for the preparation of AAO nanocomposites have been carried out [67]. In's group had illustrated a typical surface-initiated atom transfer radical polymerization (SIATRP) for the preparation of PNIPAm grafted AAO membrane composites [68]. Amine functionalities were first introduced to AAO membrane via self-assembly of 3aminopropyltriethoxysilane, following the initiator, 2bromoisobutyryl bromide, was immobilized through amination reaction. Subsequently, polymerization of NIPAm was conducted on AAO membrane, resulting in grafting of PNIPAm brushes on the membrane pore walls [69]. In addition, Chu et al. had also employed SI-ATRP to achieve poly(3-(N-2-methacryloyloxyethyl- $N, N$ dimethyl)ammonatopropanesulfonate) (PMAPS) grafted AAO composite. The linear relationship of isolated yield and molecular weight between grafted PMAPS and corresponding unbound PMAPS polymer chain via free ATRP initiator has been demonstrated, which further shed light on controlling the polymerization on AAO membranes [14]. Despite the silane sol-gel chemistry to immobilize an ATRP initiator on AAO, initiation from a poly(dopamine) layer which had been pre-adsorbed on the AAO surface, could also be applied for facilitating the introduction of functional initiators. For instance, Wang et al. had first proposed using catechol groups of poly(dopamine) to immobilize an ATRP initiator for further initiating of polymer brushes. The simple approach for covalent immobilization of an ATRP initiator and the inherent versatility of SIATRP paved the way for the preparation of diverse polymer functionalized AAO membrane [70].

Although SI-ATRP has been widely used for the preparation of polymer grafted AAO composites, rigorous deoxygenated atmosphere and indispensable addition of a transition metal catalyst constitutes harsh polymerization conditions that restrict possible use of the preparation method. Some of these limitations have been addressed by Song et al. via employing a surface-initiated RAFT (SI-RAFT) polymerization for growing polymer chains on AAO membrane [26]. In detail, a surface chain transfer agent (CTA) featuring silane end-groups was prepared and covalently bonded onto AAO membrane, subsequently RAFT polymerization was carried out from the immobilized surface CTA, thus accomplish grafting of poly(3-(methacrylamidomethyl)-pyridine) chains (Fig. 4) on AAO. The obtained AAO nanocomposites with grafted polyelectrolyte brushes could be utilized as ionexchange membranes for protein adsorption and elution.

In addition, diversiform polymerization strategies could be processed in the same AAO membrane via a half-cell reactor for constructing asymmetric nanocomposites. As illustrated in Fig. 5, simultaneous chemical polymerization, such as ATRP, dopamine self-polymerization (DOP-SP) and ring-opening metathesis polymerization (ROMP), were carried out on the respective sides of an AAO membrane to achieve asymmetric 
Fig. 4 Fabrication procedures for the grafting of polyelectrolyte brushes from AAO membrane via SI-RAFT. Reprinted with permission from ref. [26]. Copyright 2017 Elsevier

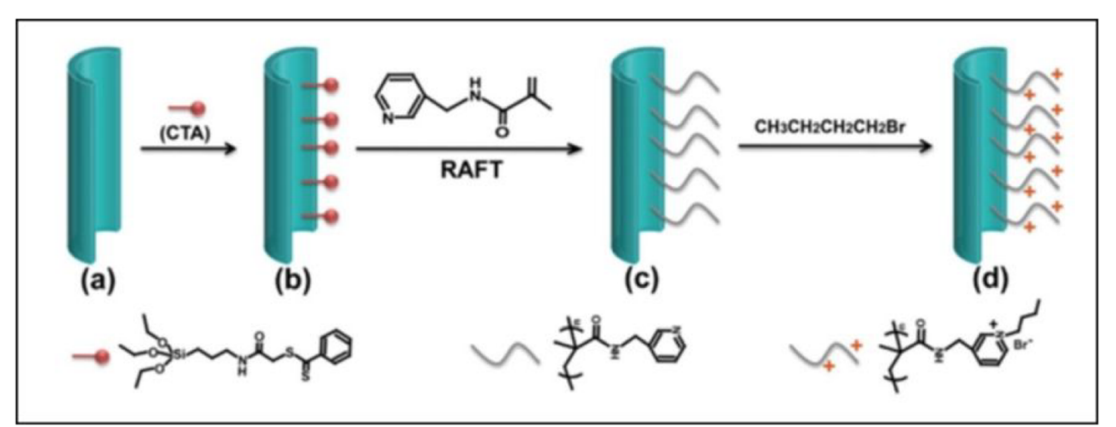

polymer functionalization [27]. The respectively grafted polymers differed in hydrophilicities or responsive properties, thus endow AAO composites with asymmetric characteristics which are promising in the separation of organic charged molecules, oil/water mixtures, and asymmetric organic catalytic reactions.

\section{Coating}

Coating strategies, such as electrochemical deposition, electroless deposition, chemical vapor deposition, and atomic layer deposition, facilitate plating of a wide variety of materials onto AAO membrane for the preparation of corresponding nanocomposites [71]. Among the different deposition methods, electrochemical deposition features an advantage because the growth rate of deposited materials could be easily adjusted. However, electrochemical deposition is limited to fabrication of conductive materials only. During electrochemical deposition, through-hole isotropic AAO membranes were utilized and deposited with conductive materials. For this, an AAO template fixed on conductive substrate is attached to the cathode and brought into contact with the deposition solution. When the electric field is applied, cations diffuse towards the cathode at which they are reduced leading to the actual electrodeposition. As a consequence, nanorods or nanotubes attached to the conductive substrate are obtained inside the template pores [72]. For example, through electrochemical deposition, $\mathrm{Cu}-\mathrm{CuAl}_{2} \mathrm{O}_{4}$ hybrids were deposited onto $\mathrm{AAO}$ membrane [73]. The composite membrane was utilized as a selective solar absorber. Owing to the incorporation of AAO substrate, the solar absorber was found to have optimized optical performance and a high anti-corrosion property when exposed to high temperatures up to $300{ }^{\circ} \mathrm{C}$. Additionally, conductive polymers are also qualified to decorate AAO membrane via electrochemical polymerization. Zhang et al. had deposited polypyrrole inside the AAO by via electrochemical polymerization. The obtained nanocomposite featured an asymmetric component distribution and displayed a $\mathrm{pH}$ - and light-modulated ion transport functionality that could be further used for creating smart nanochannel systems [74]. Similarly, the group of Lee had prepared polyaniline, polypyrrole, and poly(3,4-ethylenedioxythiphene) (PEDOT) nanostructures via electrochemical deposition in an AAO membrane [75]. Despite a single material, polymer-metal hybrid materials [76], segmented or core-shell nanostructures [77] could also be fabricated through electrochemical deposition process in AAO membrane through sequentially controlled of deposition. As reported, the obtained nanomaterials are showing great potential for energy applications [78].

On the contrary, electroless deposition is a non-galvanic plating method for surface functionalization with conductive layer. However, reducing or oxidizing agents are required
Fig. 5 Preparation processes for polymer grafting within AAO nanochannels via ATRP, ROMP, and DOP-SP techniques in halfcell reactor. Reprinted with permission from ref. [27]. Copyright 2014 Royal Society of Chemistry

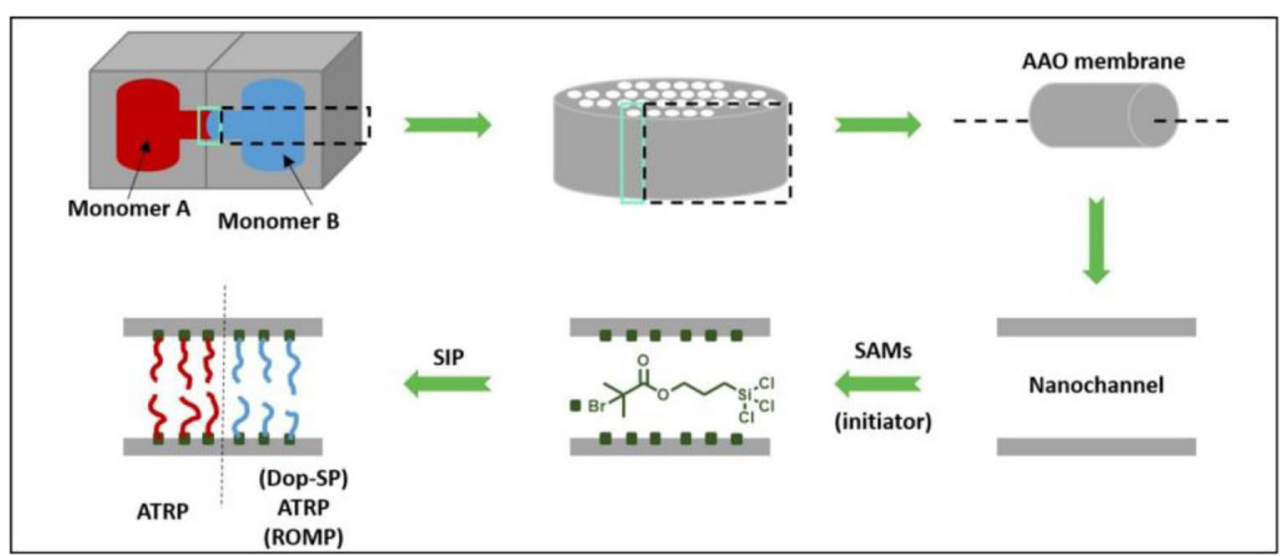


when coating metals and compounds through electroless deposition [79]. Under the effect upon surface catalyzed oxidation of reducing agent, metal ions are reduced into corresponding metal, and deposition of metal, such as copper, palladium, nickel, etc., on AAO was then achieved [75, 80]. Reddy et al. had deposited $\mathrm{Cu}$ and $\mathrm{Zn}$ onto AAO membrane via electroless deposition, and the obtained $\mathrm{Cu}-\mathrm{Zn} / \mathrm{AAO}$ composites were used for steam reforming of methanol [81].

Chemical vapor deposition (CVD) uses vapor phases for deposition, and subsequently to synthesize organic films directly onto the desired substrates, i.e., AAO. CVD is suitable for diverse materials especially to enhance productivity for those that possess limited solubility and are infusible on membrane surface [82]. For instance, Zhao et al. had prepared carbon and silicon covered AAO membrane via CVD approach. As shown in Fig. 6, carbon nanotubes (CNT) was first deposited onto AAO under atmosphere of ethylene at $800{ }^{\circ} \mathrm{C}$; further cleaned by inductively coupled plasma etching (ICPE) process, and silane was subsequently deposited on formed CNT layer; afterwards further ICPE and CNT deposition process were carried out and resulted in coaxial carbon-siliconcarbon nanotube (CNT/SiNT/CNT) arrays implanted AAO membrane. Owing to the coaxial tubular structure, the AAO composite exhibited high area capacity of approximately $6 \mathrm{~mA} \mathrm{~h} \mathrm{~cm}{ }^{-2}$, which is greater than commercial graphite when used as anodes for lithium-ion batteries [83].

Additionally, the approach by applying a vapor phase that contains reactive monomer and initiator to form chemical deposition on AAO membrane is classified as initiated CVD (iCVD) [84]. During iCVD process, monomers are preferentially adsorbed on the membrane surface, and simultaneously, initiators are decomposed under thermal or plasma excitation and formed reactive radicals. As soon as monomer and initiator radicals mix, radical initiated polymerization on the surface was triggered. iCVD yields conformal coatings with high aspect ratio and ultrathin polymer layers [85-87]. For instance, Losic et al. had utilized plasma iCVD for growing of $n$-heptyamine polymer onto AAO surface. This methodology is used to control the membrane pore size by adjusting the deposited thickness of the polymer [88]. In addition, thin layer of $\mathrm{pH}$-sensitive poly(methylacrylic acid-co-ethylene glycol dimethacrylate) was deposited onto AAO membrane via thermally initiated iCVD. Owning to the $\mathrm{pH}$ responsive character of the grafted polymer, the pore size of the modified AAO membrane could be tuned by swelling and de-swelling of grafted polymer upon changing $\mathrm{pH}$. Hence, the change in pore size facilitated size dependent separation of molecules with diverse sizes. Additionally, protonation and de-protonation of polymer brushes will also alter the surface charge of the membrane. As a result, charge interactions between membrane and permeates will also affect the membrane permeability. As a consequence, the functional membrane was also used for $\mathrm{pH}$ stimuli-responsive protein separation [89].

Differing from CVD approach, atomic layer deposition (ALD) could meet the demand for atomic layer control and conformal deposition along the thickness control at Angstrom or monolayer level [90]. Velleman et al. had coated an AAO membrane with silica via ALD using tris(tert-butoxy)silanol and trimethylaluminium as precursors. By adjusting the number of ALD deposition cycles, the coating of silicon on AAO was systematically controlled which further determined the membrane pore dimeters [91].

\section{Template wetting}

Solution-based template wetting is an effective method for the fabrication of numerous composites. In this regard, template wetting methodology that utilizes wetting phenomena to create a uniform coating of a low surface energy material, such as a polymer solution or melts, on a porous AAO template with
Fig. 6 Schematic diagram for the preparation of CNT/SiNT/CNT/ AAO composites by successive CVD. Reprinted with permission from ref. [83]. Copyright 2012 Royal Society of Chemistry

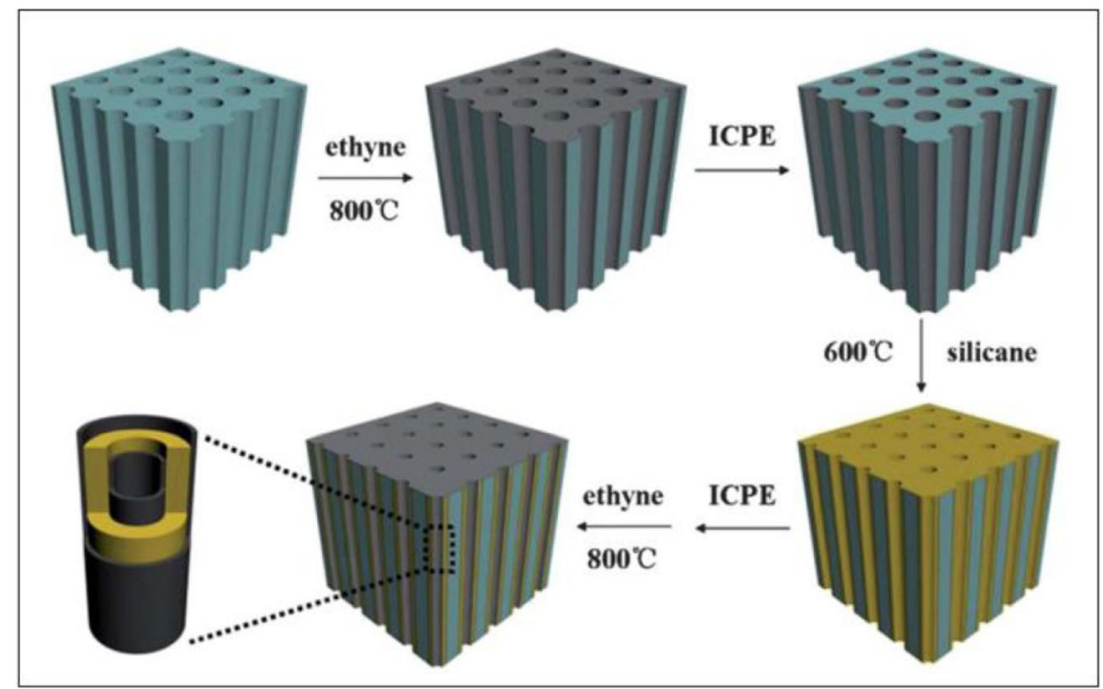


high surface energy has been widely addressed [25, 92]. Kim et al. had prepared organic nanotubes from bis-acylurea in AAO membrane via solution wetting [93]. In addition, Cannon et al. had prepared poly (2-methoxy-5-(2ethylhexyloxy)-1,4-phenylene vinylene) and poly(3hexylthiophene) covered AAO membranes via the template wetting method. The desired monomer or polymer was dissolved in suitable solvent and drop casted onto the AAO membrane. Due to surface tension effects, the applied polymer was entrapped into membrane nanopores. After evaporation of the solvent, the residual polymer layer was formed and resulted in polymer covered AAO composites [94].

In addition, by adopting AAO template wetting of photochromic molecules that assemble into crystals, nanocrystallized composites could be achieved. Via template wetting, photomechanical diarylethene nanocrystals were confined in the channels of the AAO membrane resulting in photo-powered composite bending actuators [95]. In fact, the AAO membrane is responsible for structural support and determination of bending direction, while diarylethene component provides photoresponsive ability. Upon directional UV light irritation, as revealed in Fig. 7, only a small part of crystalline nanowires in AAO membrane being directly exposed to UV light underwent photoisomerization while unexposed molecules kept their original state. The energy difference upon UV irradiation along pore orientation results in a bending motion away from the light source. The motion could be cycled multiple times in air or underwater. Besides, via template wetting methodology, Wu et al. prepared one kind lubricantinfused surface (LIS) by simple vacuum impregnation of oil into high aspect ratio AAO nanochannels. The LIS exhibited a better water repellency than the pristine AAO membrane. In addition, the thick porous structure endowed the surface with corrosion resistance, mechanical durability and self-healing properties, which enables LIS for various applications such as antifouling, anti-icing and anti-corrosion [96].

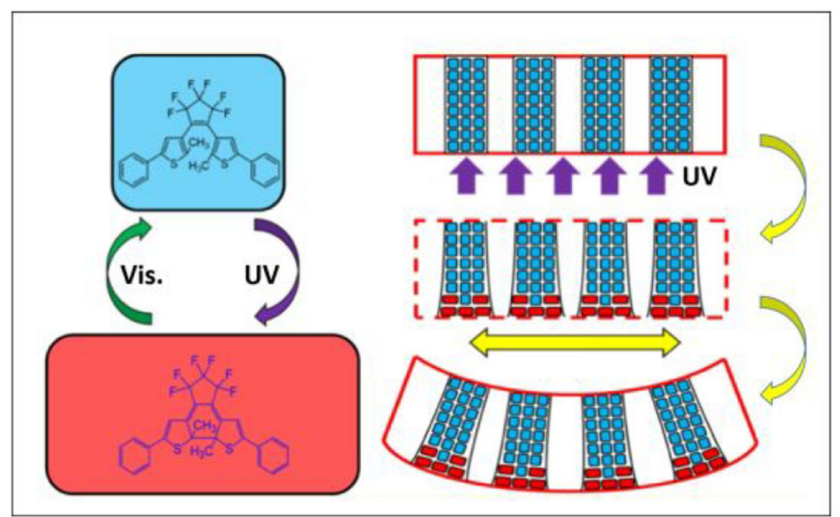

Fig. 7 Schematic photoisomerization diagram of diarylethene filled nanocrystallized AAO composite. Reprinted with permission from ref. [95]. Copyright 2019 American Chemical Society

\section{Applications}

As mentioned in the previous section, the most attractive property of AAOs is the strictly self-ordered cylindrical pores with customizable controlled pore size, pore length, and pore structure. Thus, AAO membranes provide unique possibilities in constructing nanocomposites. Utilizing the barrier layer of AAO membrane as demarcation line, AAOs can be divided as isotropic and anisotropic AAO. The isotropic AAO features double-pass cylindrical pores while anisotropic AAO has single open-end and maintains barrier layer. The membrane structure and further functionalization have great impact on the composite application, which will be discussed in this section. Figure 8 summarizes some of the typical applications of isotropic and anisotropic AAO composites ranging from water purification, protein separation, catalysis, drug delivery, smart surfaces, optical to electrical devices.

\section{Application of isotropic AAO-based nanocomposites}

The most distinguished characteristic of isotropic AAO membranes is the uniform cylindrical channel structure that spans over the entire thickness of the membrane. Therefore, isotropic AAO membranes allow further tuning of transport properties of the nanochannels. Isotropic AAO membranes feature not only high permeability, large surface area, and nanopore structure but are also stiff enough to withstand working under high pressure. Therefore, isotropic AAO membranes with tunable porosity and surface chemistry are widely used as membrane elements for specialized transport processes in the field of protein gating, water purification, photonic device, battery and sensor [91].

\section{Protein gating}

As reported, nanoporous AAO membranes are widely employed in the construction of protein gating composite membranes in combination with diverse biocompatible

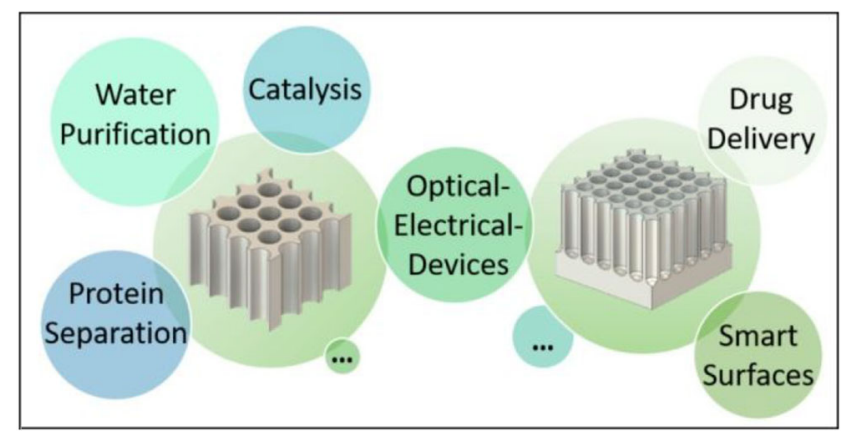

Fig. 8 Typical applications of isotropic and anisotropic AAO composites ranging from water purification, protein separation, catalysis, drug delivery, smart surfaces, optical and electrical devices, etc. 
organic and inorganic materials. For example, Chen et al. had adopted sputtering of $\mathrm{Au}$ on an AAO membrane for reducing the pore diameter from 27 to $10 \mathrm{~nm}$, followed by modification of the membrane to graft polyhistidine-tagged proteins. This functionalized AAO can act as a biological membrane, which is allowing sequential protein binding and release/pumping cycles. Thus, the fabricated membrane realized the application in bio-pharmaceutical field [97].

Additionally, Lee et al. had prepared double stimuliresponsive gate membranes by grafting PAA and PNIPAm from one side of an isotropic AAO membrane, respectively (Fig. 9). The two distinguishable gates of the membrane can be individually modulated by temperature and $\mathrm{pH}$. For instance, at $40^{\circ} \mathrm{C}$ and $\mathrm{pH} 3$, all polymer brushes are dehydrated leaving the gate opened for matter permeance. On the contrary, the gate could be closed by either increasing the temperature above $40^{\circ} \mathrm{C}$ or adjusting the $\mathrm{pH}$ value above 6 , or both, so enable closed state of composite membrane. This autonomous on and off gating membrane reveals controllability in storing and releasing of molecules such as bovine serum albumin (BSA), therefore illustrating potential prospective in mimicking cell membrane [98].

Similarly, Tufani et al. had prepared a Janus AAO membrane composite for protein gating by depositing poly(methylacrylic acid-co-ethylene glycol dimethacrylate), i.e., P(MAA-co-EGDMA), and poly(4-vinylpyridine-coethyleneglycol dimethacrylate), i.e., P(4VP-co-EGDMA), on each side of an isotropic AAO template via iCVD. Through the control of $\mathrm{pH}$ on each side of the composite, permeation of BSA molecules could be modulated on demand [99]. Further, by anchoring of specific proteins onto the inner pore surface, the membrane composites are capable for selective protein separation. For instance, when grafting lysine onto an AAO membrane, the functionalized composite is suitable for removal of bilirubin owing to the specific selectivity of grafted protein [100]. Besides, a simple deposition of a thin AAO membrane with small pore size $(20-30 \mathrm{~nm})$ on top of a silicon substrate enabled a biomolecule separation platform. The composite membrane could be used for electrostatic sieving of biomolecules. For example, when adjusting $\mathrm{pH}$ to 4.7 , the same as the isoelectric point of BSA, BSA molecules existed in a neutral state, while bovine hemoglobin $(\mathrm{BHb})$ molecules were positively charged owing to their inherent higher isoelectric point. As a consequence, when passing a mixed BSA and $\mathrm{BHb}$ protein solution through the membrane, the charged $\mathrm{BHb}$ molecules were blocked, while BSA molecules were selectively isolate [101].

\section{Purification}

AAO membranes bearing functionalized nano-cylindrical pores are utilizable for purification owing to their ability of selectively blocking viruses, small organic molecules, salts as well as other hazardous metal ions. In an exemplary work, Liu et al. had prepared amphiphilic AAO membranes for water "dry condensation" [102]. An amphiphilic AAO membrane was fabricated by modifying one side of the AAO membrane with dodecyltrichlorosilane to increase surface hydrophobicity, while maintaining the hydrophilic character of the other side. The hydrophobic surface prevents the accumulation of water droplets, hence exhibiting a self-cleaning property. The authors showed that this membrane is capable of a "dry condensation" in such way that water droplets are rapidly driven from the hydrophobic surface through the hydrophilic porous channel to the hydrophilic side. Therefore, this material has the potential to be applied in manifold of applications ranging from water-harvesting and phase-change-based desalination to energy generation and transfer.

When photochromic groups (such as spiropyran [103], diarylethene [104], or azobenzene [105]) are combined with AAO composite, smart optical materials could be fabricated. For instance, a photo-induced separation membrane can be achieved by grafting of azobenzene groups onto a AAO membrane via SAM approach [106]. The immobilized azobenzene groups are capable to undergo a cis-trans isomerization upon $\mathrm{UV} /$ vis stimulation, inducing a change of the membrane permeability. The azobenzene-AAO composite membrane is schematically illustrated in Fig. 10. Owing to the rapid
Fig. 9 Dual stimuli-responsive AAO composite with temperature-controlled PNIPAm gate and $\mathrm{pH}$-controlled PAA gate. Reprinted with permission from ref. [98]. Copyright 2016 American Chemical Society

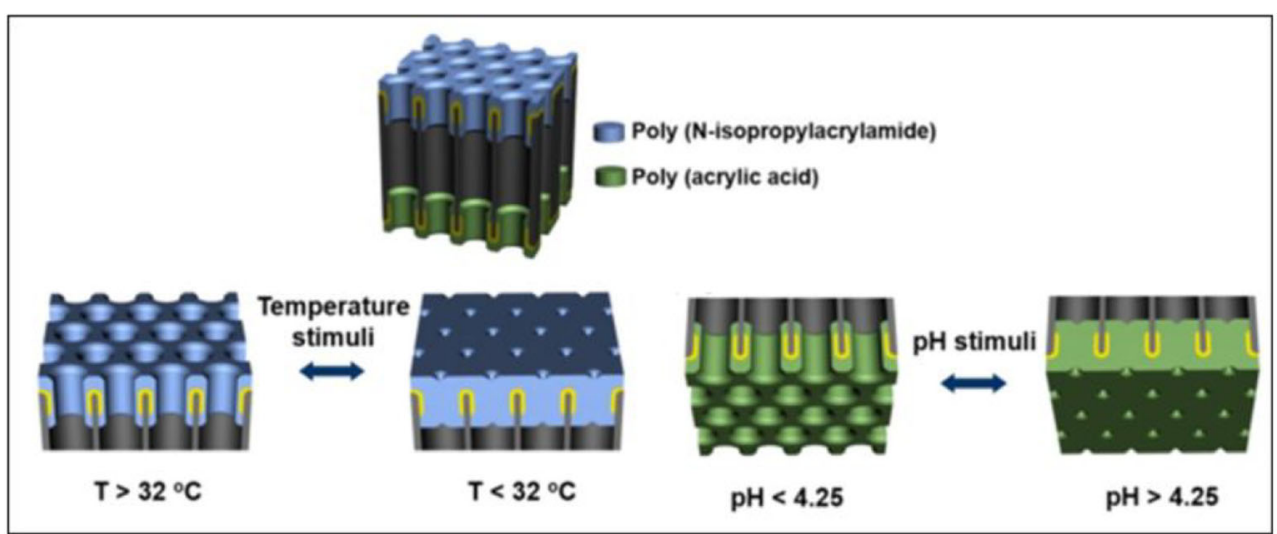




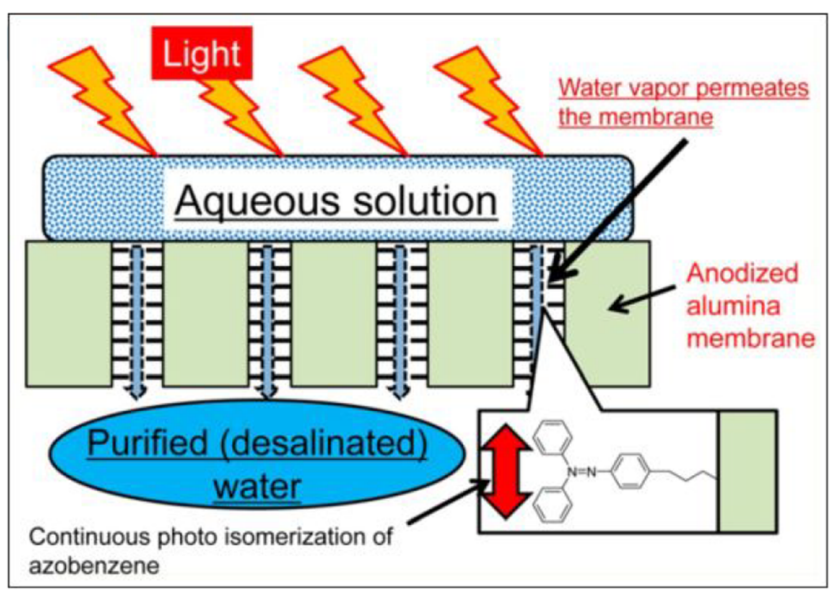

Fig. 10 Schematic illustrates of azobenzene modified alumina membrane for water purification and desalination. Reprinted with permission from ref. [106]. Copyright 2015 American Chemical Society

isomerization of azobenzene groups on membrane surface, vaporization of water is induced and promotes infiltration of aqueous solution, while the dissolved dyes, salt or protein molecules are rejected from permeation. As a consequence, the azobenzene-AAO composites are qualified for water purification and seawater desalination.

Additionally, Song et al. had prepared AAO composites for hazardous heavy metal ion removal from aqueous solution. In this regard, polyrhodanine was immobilized on AAO membrane via vapor deposition polymerization and the obtained polyrhodanine-AAO composite filtration setup is illustrated in Fig. 11 [107]. Attributing to the strong metal binding sites of

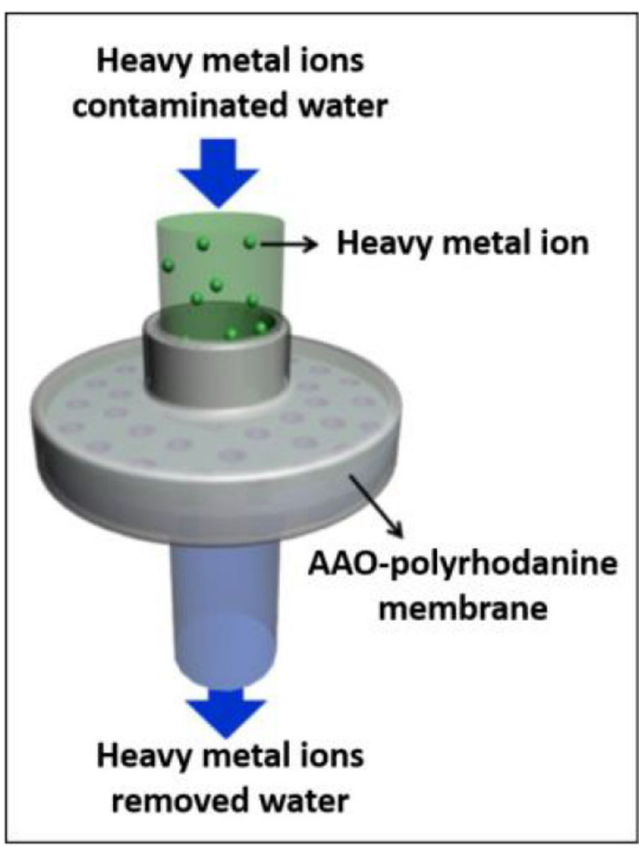

Fig. 11 Schematic diagram of AAO-polyrhodanine composite membrane for the use of heavy metal ions remove. Reprinted with permission from ref. [107]. Copyright 2011 Elsevier polyrhodanine, the polyrhodanine-AAO composite reveals high metal uptake capability towards metal ions such as $\mathrm{Hg}(\mathrm{II}), \mathrm{Ag}(\mathrm{II})$, and $\mathrm{Pt}(\mathrm{I})$ [108]. Hence, when an aqueous mixture was passed through polyrhodanine-AAO composite membrane, metal ions were adsorbed by the immobilized polyrhodanine. Additionally, the composite membrane could be recycled and used again for heavy metal removal by further deposition of polyrhodanine.

Inspired by sand filter, nanoparticle-embedded AAO composites were prepared for finer filtration of small molecules in the nanoscale dimension. Phuong et al. had incorporated diverse polystyrene (PS) nanoparticles inside AAO channels by varying the size of entrapped nanoparticle from 24 to $150 \mathrm{~nm}$, as illustrated in Fig. 12, and the permeability of the membrane composite was then modulated. In addition, upon functionalization of embedded nanoparticles with arginine/ phenylalainine peptide groups, filtration based on charge selection was achieved for the separation of charged molecules, such as methylene blue from aqueous solution. Consequently, such a nano-sand filter is expected to be applied in water purification [109].

Additionally, Petukhov et al. had prepared an AAO supported graphene oxide composite membrane via spin-coating and demonstrated the usage of the obtained membrane for pressure-assisted filtration of gas de-humidification [110]. On one hand, the graphene oxide layer exhibited high permeability towards water and water soluble gases like $\mathrm{CO}_{2}$, while acting as a barrier to most gases such as $\mathrm{CH}_{4}, \mathrm{~N}_{2}, \mathrm{O}_{2}$, and $\mathrm{C}_{4} \mathrm{H}_{10}$. On the other hand, $\mathrm{AAO}$ acted as a stable support and showed high affinity towards graphene oxide sheets via inherent hydrogen oxide groups; additionally, $\mathrm{Al}^{3+}$ cations formed an interlocking between graphene oxide sheets, which ensured the composite to be stable enough for gas de-humidification.

\section{Catalysis}

Besides being used as obstacles for unwanted substances, isotropic AAO membranes featuring highly arranged nanochannels are also ideal fundamental materials for promoting flow-through of desired materials, such as in catalysis. The porous structure of AAO membranes facilitates a better assembling of catalysts, and the inherent high thermal and mechanical properties of AAO membrane enable the utilization under harsh working conditions [111]. For e $x$ a m ple, Li u t a 1 . had grafted poly(methacrylatoethyltrimethylammonium chloride) polymer brushes onto AAO channels via SI-RAFT polymerization, followed by a further in situ reduction of $\mathrm{Au}$ nanoparticles inside the nanopores, thus resulting in the stabilization of $\mathrm{Au}$ nanoparticles in the AAO membrane. This AAO composite was applied for Au-mediated catalytic reduction of 4-nitrophenol under flow-through conditions. Channels of this composite membrane act as 


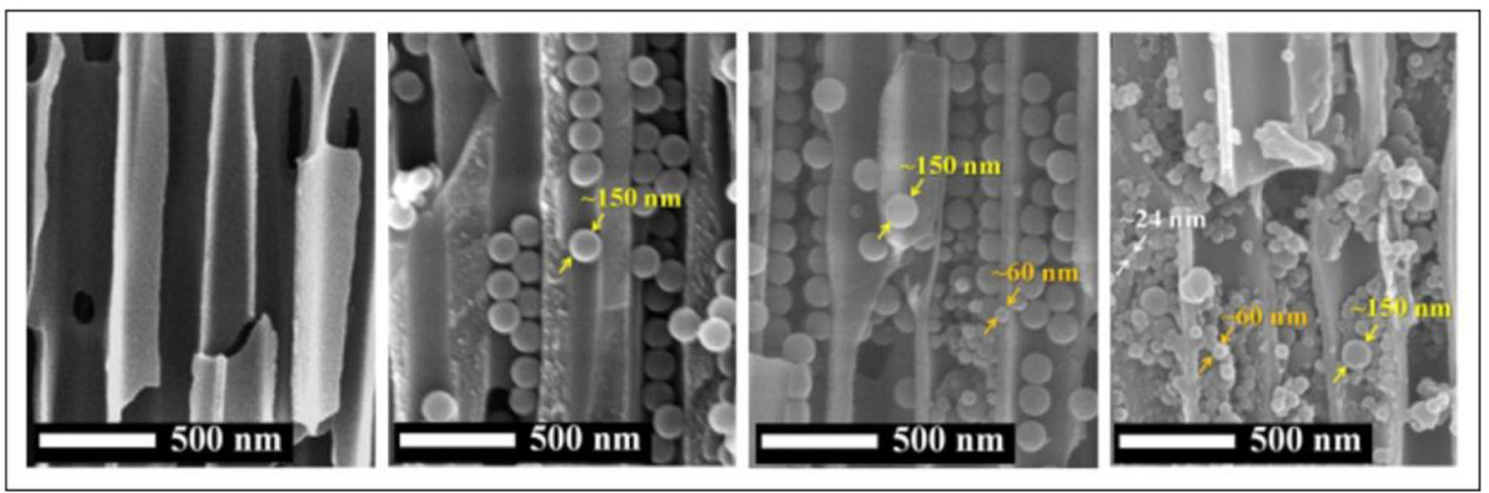

Fig. 12 Cross-section view of AAO membrane and embedded nanoparticle as nano-sand filter. Reprinted with permission from ref. [109]. Copyright 2016 Springer Nature

nanosized reactors, and the high aspect ratio of the porous membrane and large amount of homogenously restrained $\mathrm{Au}$ nanoparticle attributed to a highly catalytic performance [30]. Additionally, Yang et al. had incorporated metal-organic frameworks (MOFs) within an isotropic AAO membrane. The AAO-MOFs composite had increased the compatibility, dispersity and stability of MOFs as catalyst reactor for the Knoevenagel condensation reaction [112]. Compared with metal catalysis, immobilization of enzyme catalysis is relatively more difficult owing to the high retention of protein activity upon chemical modification. In order to solve this problem, Lu et al. had proposed immobilization of enzyme in hierarchically structured AAO membrane. As shown in Fig. 13, enzyme catalysts were entrapped into mesoporous silica that was grown inside an AAO membrane. Further, an additional mesoporous nanoparticle film was covered on both sides of the AAO composite, benefiting the adaptive permeability, strong adhesion and smart integration. The resulting AAO-silica-enzyme composite membrane has demonstrated size-selective permeability of small molecules. When Trypsin was entrapped within the composite membrane, it was observed to promote the bio-catalytic hydrolysis of $\mathrm{N} \alpha$ - $p$-tosyl-L-arginine methyl ester hydrochloride while keep constant activity even running up to 30 cycles [113].

Additionally, Hussain et al. had prepared embedded ruthenium $(\mathrm{Ru})$ in an $\mathrm{AAO}$ by reduction of ruthenium precursor via a sonochemical method, and the obtained Ru@AAO was able to catalyze the oxidation reaction of 1-naphthalenemethanol with higher catalytic activity owing to the porous structure and surface area of AAO [114].

\section{Photonic- and electrical-related devices}

Other key applications of isotropic AAO membranes include combination with conductive materials for the constructing of optical, electrical or photoelectrical devices. Via vapor deposition, Zhou et al. had prepared an AAO-based plasmonic absorber that can absorb light in a wide wavelength range [115]. During the process, gold nanoparticles are finely deposited on top surface and inner walls of the AAO membrane in a hierarchical distribution along the pore walls. The assembled gold nanoparticles are larger and sparser on the top surface, whereas smaller and more density packed nanoparticles

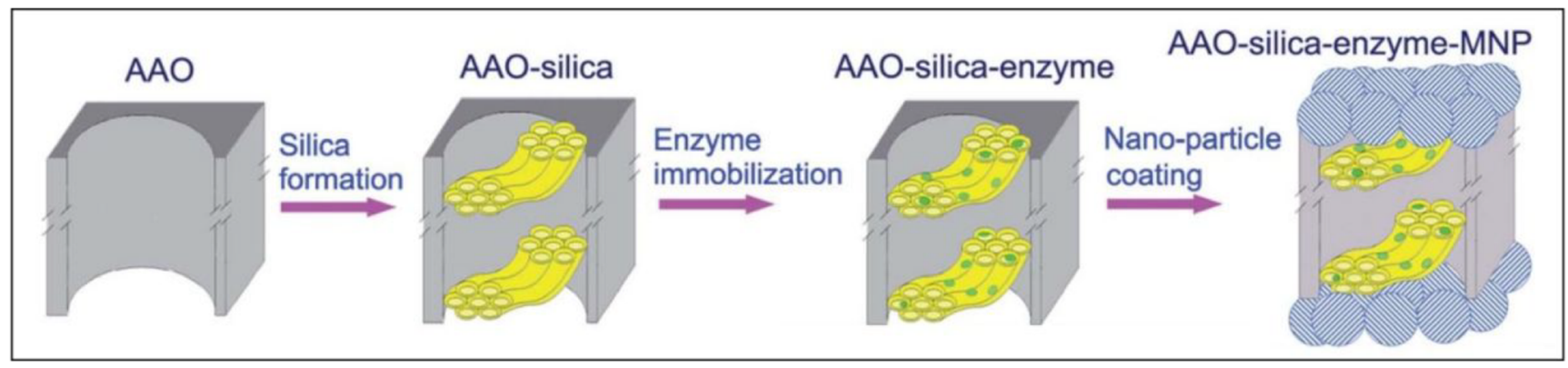

Fig. 13 Schematic illustration of enzyme incorporated AAO composite. Reprinted with permission from ref. [113]. Copyright 2012 Royal Society of Chemistry 
were observed inside the membrane channel. The heterogeneous distribution of gold nanoparticles and isotropic porous structure enabled AAO composites with efficient and broadband plasmonic absorption, which can be further used for solar steam generation.

Furthermore, Kwon et al. had fabricated micro-solid oxide fuel cells from isotropic AAO templates. In their study AAO membranes acted as substrates of the fuel cells. Unlike traditional foil substrates, the porous structure of AAO membranes provides gas-channels that improve the thermo-mechanical stability of the device further [116]. In addition, porous AAO membranes have been used as separators for lithiumion batteries. The porous structure of AAO membranes minimizes ionic resistance and shortens diffusion path of ions, which in turn enhance the discharge capacity of the battery. Additionally, the AAO separator has a high affinity to electrolytes, and good ionic conductivity. As a result, compared with commercial separators, porous AAO membranes are found to have better mechanical stability, and also showed better performances on electrolyte infiltration and retention [117].

Nanoporous isotropic AAO membranes are also widely used in sensing applications [118]. In comparison with flat sensor materials, porous AAO membranes are protruding because of their large surface area [54]. AAO-based sensors are widely utilized for pressure, humidity, chemical or bio-related sensing. For instance, a porous AAO membrane was incorporated into a pressure sensor device for isolating conductive wrinkled graphene layers which prevent excessive energy consumption from nonworking condition. The introduction of isolating AAO layer not only avoids energy combustion in the "off" state but also improves the sensitivity of the pressure sensor by taking advantage of AAO porous structure [119]. Besides, Ma et al. had constructed an AAO membrane as air filter in an optical gas sensor. With the introduction of the AAO membrane, the system can prevent particle contamination above $70 \mathrm{~nm}$. By varying the incorporated pore size of AAO, the sensitivity of sensor system to particle contamination could be fine-tuned [120]. Additionally, Tabrizi et al. had designed a biosensor based on AAO via immobilized with DNAzyme. The obtained biosensor is able to detect lead(II) ions with different concentrations ranging from 50 to 3200 $\mathrm{nM}[121]$.

As a versatile substrate, AAO membranes could be also be used to prepare nanofluidic devices for osmotic energy conversion. Xin et al. had deposited silk nanofibril (SNF) on to variable-channel AAO membrane for constructing a composite membrane for osmotic energy harvesting within a reverse electrodialysis device. The SNF dominated the ion transportation owing to its surface negativity, while AAO provide tunable pores with amphoteric groups enable the establishing of asymmetric nanofluidic system [122].

\section{Application of anisotropic AAO-based nanocomposites}

The major application of anisotropic AAO membranes is patterning of uniform nanostructures, and in these processes AAO membranes are used as sacrificial templates. However, AAO membranes can also be maintained as substrates after nano-patterning for preparing nanostructured surfaces that are applied as antifouling and adhesive composite materials. Additionally, the large number of nanocavities are facilitating to load different materials, e.g. dye molecules, drug molecules, nanoparticles, and thus the filled AAO composites could be further used for storage and delivery of corresponding molecules. In this section, applications of nanocomposites that are established from anisotropic AAO membrane are discussed.

\section{Smart surfaces}

AAO membranes offer the opportunity to fabricate highly aligned nanostructured films, which could be used as structured functional surfaces with superior wettability for potential industrial application. Kim et al. had prepared a $\mathrm{AAO} /$ polydimethylsiloxane (PMDS) hybrid mold, where the AAO template was attached to PDMS plate which is flexible and can be used for roll-to-roll nanoimprinting [123]. However, for the fabrication of high-performance films only unitary nanostructures are woefully inadequate, hence, structural features such as pillar size, aspect ratio, tip shape, tilting angle, and hierarchical structures should also be considered [124-128]. Zhang et al. had incorporated anionic and zwitterionic polymers into AAO membranes and consequently smart gel surfaces with antifouling properties could be obtained. The surfaces showed underwater superoleophobicity with ultralow oil adhesion, which are usually observed for prohibited algae adhesion. This kind of gel surface is promising for usage in bio-adhesion industry or as antifouling coatings [129]. In addition, complex topography could also be built on AAO membrane by adopting the same strategy. Du et al. had fabricated underwater a micro/nano-brush dual structural surface on the substrate of AAO template from modulating template channels. The surface consisted of numerous poly(acrylic acid) gel pillars. The rough surface could entrap large amount of water to form underwater "lotus" state and exhibited underwater superoloeophobic with low adhesion to oil droplets. Additionally, ATRP initiator was trapped in PAA gel microbrushes, and subsequently, the micro-brush could be further modified with stimuli-responsive polymer nano-brushes via SI-ATRP. Therefore, the surface was endowed with smart properties. For instance, by modifying with thermoresponsive PNIPAm brushes, the surface exhibited a low oil adhesion at $20{ }^{\circ} \mathrm{C}$, and the adhesion increased when the 
temperature raised to $60{ }^{\circ} \mathrm{C}$. Further, polyelectrolyte, poly $(3-$ sulfopropyl methacrylate potassium salt), modified surfaces revealed an increased oil adhesion with the addition of salt and featured exceptional performance against algal attachment, which paved the way towards potential application for the design of antifouling materials in marine industry [130].

Similarly, by slight adjustment, a PAA-AAO composite is capable to be used as adhesive. For this, PAA hydrogel-pillars were fabricated via free radical polymerization inside the pores of an anisotropic AAO membrane. The hydrogelpillars provided simultaneous friction on both side of the membrane. Moreover, attributing to the $\mathrm{pH}$ stimuliresponsive property of PAA brushes, the membrane composites showed in situ, stable, fast, and durable friction switch between low and high states under high load of $40 \mathrm{~N}$. The membrane composites were used for mimicking a gecko's feet, particularly, the reversible attachment and detachment. Intriguingly, the strategy mentioned within this work facilitated the design of multi-stimuli-responsive interface-actuated devices for the potential application as underwater robots, sensors and other bionic devices [131].

\section{Drug delivery}

The nanopores of anisotropic AAO membrane are applicable as cavities for drug storage. For instance, Kwak and colleagues had used paclitaxel for investigation of drug loading and releasing from an AAO membrane. They revealed that the amount of released drug decreased upon increasing the pore depth from $0.5 \mu \mathrm{m}$ to $4 \mu \mathrm{m}$, while the pore diameter had not substantial impact on the drug release [132]. In addition, SI-ATRP of PNIPAm was employed by the group of Zapotoczny to transform an anisotropic AAO membrane into a pulsatile releasing platform as revealed in Fig. 14. Since PNIPAm could undergo conformational changes upon temperature changes below or above its lower critical solution temperature (LCST), the grafted PNIPAm brushes served as thermally responsive valves that displayed an autonomous gate control on the membrane pores, and thus endowed the controlled pulse release of entrapped dye molecules. At high temperature, PNIPAm brushes were dehydrated and collapsed, thus resulting in open pores and pre-entrapped calcein molecules could be released. On the contrary, upon decreasing temperature, PNIPAm brushes underwent rehydrating into stretched chains that blocked the membrane pores. As a result, calcein molecules were blocked from being released from the template. By further adjusting the temperature, reversible control of releasing could be achieved. The loading capacity and releasing rate could be also easily controlled via regulating of pore diameter and length of AAO membrane, and hence the modified membrane showed potential for application as nano/microfluidic systems [133].

\section{Compositive nanodevices}

By taking advantage of moderated transparency and a low absorption coefficient, anisotropic AAO membranes could also be build-up as optical- and energy- related devices. And indeed, AAO membranes were incorporated for the fabrication of liquid crystal display (LCD) panels [134]. As reported, liquid crystal molecules were filled into the nanocavities of an AAO membrane and due to capillary forces the liquid crystals were accurately aligned inside the pores. Hence, the AAO acted as an alignment layer with the LCD exhibiting excellent electro-optical performance.

In another example, a low temperature $\left(32-230{ }^{\circ} \mathrm{C}\right)$ thermochemical heat storage (THS) system was built based on AAO membranes by impregnating various salts into the AAO nanocavities under vacuum. In a THS system, upon discharging humid air passed through cylindrical pores of AAO, adsorption of water vapor occurred; on the contrary, upon charging hot dry air is passed through the same pores and vaporize adsorbed water. The desorption enabled heat storage while adsorption heat recovering. Owing to the adjustability of the AAO structure, the storage capacity is controllable, which in turn provided insight for the development of advanced energy storage materials [135]. Additionally, anisotropic AAO nanocomposites have been explored as colorimetric sensors [136], self-lubricated membranes [35], and bio-sensing chips [137].
Fig. 14 Molecule loading and releasing from PNIPAm grafted AAO nanovalves. Reprinted with permission from ref. [133]. Copyright 2013 American chemical Society

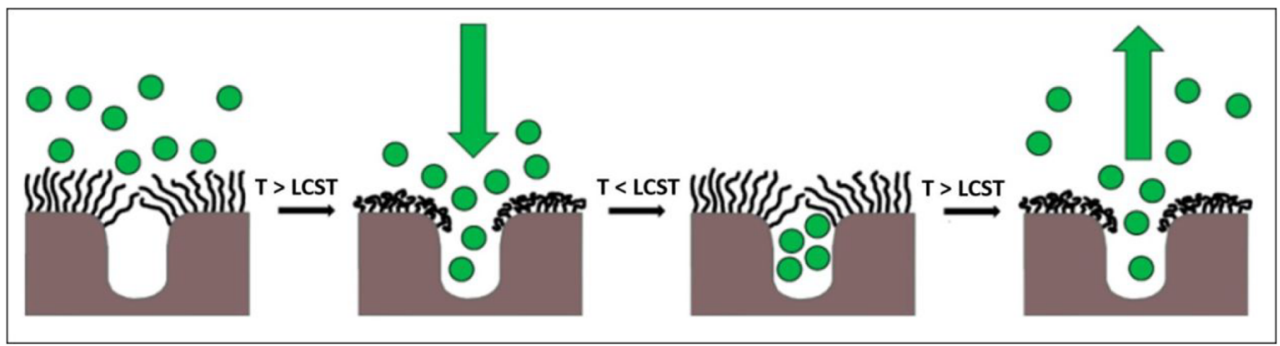




\section{Conclusion and outlook}

To conclude, taking advantage of uniform nanostructure, controllable geometrics, excellent biocompatibility, thermal, mechanical, and organic chemical resistance as well as the low fabrication costs, AAO templates have attracted plenty of interest in the field of nanotechnology, specifically for the fabrication of nanocomposites for the development of functional devices [138-140]. In this review, we summarized advanced methodologies for constructing AAO-based composites. In addition, relevant applications depending on isotropic and anisotropic type AAO were further discussed. Innovative methodologies on designing and fabricating AAO nanocomposite are application driven. Indeed, the significant number of publications in this field now exceeds the size of one hundred per year. Hence the perspective on future AAO nanocomposite will be specific on enhancing of properties when devoted of AAO membrane into different field, for instance, raise the storage capacity of electronic device, enhance entrap and release efficiency of drug storage template, increase filtration efficiency of filters, faster sensing reaction of sensors, or explore complex pore structures for preparing hierarchical smart pillar-array-surfaces. AAO nanocomposites bearing a fruitful variability are highly promising to be applied in future areas such as energy, bio-pharmaceutical and food industry. Depending on the unpredictable needs, AAO membranes are capable to fulfill the demand due to their high variability in dimensions. However, from laboratory work to commercial products, numerous challenges are required to be solved. In fact, we could postulate that more efforts in the field of basic research should be devoted to develop substantially better electrochemical oxidation of aluminum and of forming a specific porous structure of oxide layers. In addition, it is essential to improve the existing functionalization methods in order to fabricate AAO composite materials with enhanced stability and durability.

Funding Open Access funding provided by Projekt DEAL. XH gratefully acknowledges the China Scholarship Council (CSC grants 201506240019) for partial financial support of this work.

\section{Compliance with ethical standards}

Conflict of interest The authors declare that they have no conflict of interest.

Open Access This article is licensed under a Creative Commons Attribution 4.0 International License, which permits use, sharing, adaptation, distribution and reproduction in any medium or format, as long as you give appropriate credit to the original author(s) and the source, provide a link to the Creative Commons licence, and indicate if changes were made. The images or other third party material in this article are included in the article's Creative Commons licence, unless indicated otherwise in a credit line to the material. If material is not included in the article's Creative Commons licence and your intended use is not permitted by statutory regulation or exceeds the permitted use, you will need to obtain permission directly from the copyright holder. To view a copy of this licence, visit http://creativecommons.org/licenses/by/4.0/.

\section{References}

1. Li Q, Li X, Wageh S, al-Ghamdi AA, Yu J (2015) CdS/Graphene Nanocomposite Photocatalysts. Adv Energy Mater 5:1500010. https://doi.org/10.1002/aenm.201500010

2. Komarneni S (1992) Feature article Nanocomposites. J Mater Chem 2:1219. https://doi.org/10.1039/jm9920201219

3. Leontiev AP, Volkova OY, Kolmychek IA, Venets AV, Pomozov AR, Stolyarov VS, Murzina TV, Napolskii KS (2019) Tuning the optical properties of hyperbolic metamaterials by controlling the volume fraction of metallic nanorods. Nanomaterials 9:739. https://doi.org/10.3390/nano9050739

4. Guozhong C (2004) Nanostructures and nanomaterials: synthesis, properties and applications. World Sci

5. Aruna ST, Mukasyan AS (2008) Combustion synthesis and nanomaterials. Curr Opin Solid State Mater Sci 12:44-50. https://doi.org/10.1016/j.cossms.2008.12.002

6. Gogotsi Y (2006) Nanomaterials handbook. CRC press

7. Keller F, Hunter MS, Robinson DL (1953) Structural features of oxide coatings on aluminum. J Electrochem Soc 100:411. https:// doi.org/10.1149/1.2781142

8. Lee W, Park SJ (2014) Porous anodic aluminum oxide: anodization and templated synthesis of functional nanostructures. Chem Rev 114:7487-7556. https://doi.org/10.1021/cr500002z

9. Md Jani AM, Losic D, Voelcker NH (2013) Nanoporous anodic aluminium oxide: advances in surface engineering and emerging applications. Prog Mater Sci 58:636-704. https://doi.org/10.1016/ j.pmatsci.2013.01.002

10. Mijangos C, Hernández R, Martín J (2016) A review on the progress of polymer nanostructures with modulated morphologies and properties, using nanoporous AAO templates. Prog Polym Sci 54 55:148-182. https://doi.org/10.1016/j.progpolymsci.2015.10.003

11. Kim TY, Jeong SH (2008) Highly ordered anodic alumina nanotemplate with about $14 \mathrm{~nm}$ diameter. Korean J Chem Eng 25:609-611. https://doi.org/10.1007/s11814-008-0102-6

12. Steinhart M (2008) Supramolecular organization of polymeric materials in nanoporous hard templates. In: Self-assembled nanomaterials II. Springer, pp 123-187

13. Zhang F, Liu X, Pan C, Zhu J (2007) Nano-porous anodic aluminium oxide membranes with 6-19 nm pore diameters formed by a low-potential anodizing process. Nanotechnology 18:345302. https://doi.org/10.1088/0957-4484/18/34/345302

14. Chu CW, Higaki Y, Cheng CH, Cheng MH, Chang CW, Chen JT, Takahara A (2017) Zwitterionic polymer brush grafting on anodic aluminum oxide membranes by surface-initiated atom transfer radical polymerization. Polym Chem 8:2309-2316. https://doi. org/10.1039/c7py00045f

15. Ran C, Ding G, Liu W, Deng Y, Hou W (2008) Wetting on Nanoporous alumina surface: transition between Wenzel and Cassie states controlled by surface structure. Langmuir 24:9952 9955. https://doi.org/10.1021/la801461j

16. Song Z, Fathizadeh M, Huang Y, Chu KH, Yoon Y, Wang L, Xu WL, Yu M (2016) TiO2 nanofiltration membranes prepared by molecular layer deposition for water purification. J Membr Sci 510:72-78. https://doi.org/10.1016/j.memsci.2016.03.011

17. Huang X, Mutlu H, Theato P (2020) A bioinspired hierarchical underwater superoleophobic surface with reversible $\mathrm{pH}$ response. Adv Mater Interfaces 7:2000101. https://doi.org/10.1002/admi. 202000101 
18. Guo Y, Zhang Y, Liu H, Lai SW, Li Y, Li Y, Hu W, Wang S, Che $\mathrm{CM}$, Zhu D (2010) Assembled organic/inorganic $\mathrm{p}-\mathrm{n}$ junction interface and photovoltaic cell on a single nanowire. J Phys Chem Lett 1:327-330. https://doi.org/10.1021/jz9002058

19. Oh JH, Lee HW, Mannsfeld S, Stoltenberg RM, Jung E, Jin YW, Kim JM, Yoo JB, Bao Z (2009) Solution-processed, highperformance n-channel organic microwire transistors. Proc Natl Acad Sci 106:6065-6070. https://doi.org/10.1073/pnas. 0811923106

20. Shi W, Song S, Zhang H (2013) Hydrothermal synthetic strategies of inorganic semiconducting nanostructures. Chem Soc Rev 42: 5714-5743. https://doi.org/10.1039/c3cs60012b

21. Rath A, Theato P (2020) Advanced AAO templating of nanostructured stimuli-responsive polymers: hype or hope? Adv Funct Mater 30:1902959. https://doi.org/10.1002/adfm.201902959

22. Santos A, Kumeria T, Losic D (2013) Nanoporous anodic aluminum oxide for chemical sensing and biosensors. TrAC-Trends Anal Chem 44:25-38. https://doi.org/10.1016/j.trac.2012.11.007

23. Sato A, Pennec Y, Shingne N, Thurn-Albrecht T, Knoll W, Steinhart M, Djafari-Rouhani B, Fytas G (2010) Tuning and switching the hypersonic phononic properties of elastic impedance contrast nanocomposites. ACS Nano 4:3471-3481. https:// doi.org/10.1021/nn100519h

24. Muanchan P, Kurose T, Ito H (2019) Replication of mesoscale pore one-dimensional nanostructures: surface-induced phase separation of polystyrene/poly(vinyl alcohol) (PS/PVA) blends. Polymers (Basel) 11:1039. https://doi.org/10.3390/ polym11061039

25. Song G, She X, Fu Z, Li J (2004) Preparation of good mechanical property polystyrene nanotubes with array structure in anodic aluminum oxide template using simple physical techniques. J Mater Res 19:3324-3328. https://doi.org/10.1557/JMR.2004.0427

26. Song C, Wang M, Liu X, Wang H, Chen X, Dai L (2017) Fabrication of high-capacity polyelectrolyte brush-grafted porous AAO-silica composite membrane via RAFT polymerization. Mater Sci Eng C 78:748-755. https://doi.org/10.1016/j.msec. 2017.03.042

27. Ma S, Liu J, Ye Q, Wang D, Liang Y, Zhou F (2014) A general approach for construction of asymmetric modification membranes for gated flow nanochannels. J Mater Chem A 2:8804-8814. https://doi.org/10.1039/c4ta00126e

28. Wang W-C, Wang J, Liao Y, Zhang L, Cao B, Song G, She X (2010) Surface initiated ATRP of acrylic acid on dopaminefunctionalized AAO membranes. J Appl Polym Sci 117:534541. https://doi.org/10.1002/app.30939

29. Wassel E, Es-Souni M, Laghrissi A, Roth A, Dietze M, Es-Souni M (2019) Data supporting polymerization of anti-fouling polymer brushes polymerized on the pore walls of porous aluminium and titanium oxides. Data Br 23:103702. https://doi.org/10.1016/j.dib. 2019.103702

30. Liu J, Ma S, Wei Q, Jia L, Yu B, Wang D, Zhou F (2013) Parallel array of nanochannels grafted with polymer-brushes-stabilized $\mathrm{Au}$ nanoparticles for flow-through catalysis. Nanoscale 5:11894 11901. https://doi.org/10.1039/c3nr03901c

31. Kim JS, Kim TG, Kong WH, Park TG, Nam YS (2012) Thermally controlled wettability of a nanoporous membrane grafted with catechol-tethered poly( $\mathrm{N}$-isopropylacrylamide). Chem Commun 48:9227-9229. https://doi.org/10.1039/c2cc32233a

32. Song C, Shi W, Jiang H, Tu J, Ge D (2011) PH-sensitive characteristics of poly(acrylic acid)-functionalized anodic aluminum oxide (AAO) membranes. J Membr Sci 372:340-345. https://doi. org/10.1016/j.memsci.2011.02.017

33. Cai Y, Chen D, Li N, Xu Q, Li H, He J, Lu J (2018) A smart membrane with antifouling capability and switchable oil wettability for high-efficiency oil/water emulsions separation. J Membr Sci 555:69-77. https://doi.org/10.1016/j.memsci.2018.03.042
34. Lee L-R, Karapala VK, Lin Y-L, He HC, Chen JT (2020) Intelligent environmental sensing: fabrication of switchable, reusable, and highly sensitive gas sensors with spiropyran-grafted anodic aluminum oxide templates. J Phys Chem C 124:11870 11876. https://doi.org/10.1021/acs.jpcc.0c01129

35. Vengatesh P, Kulandainathan MA (2015) Hierarchically ordered self-lubricating superhydrophobic anodized aluminum surfaces with enhanced corrosion resistance. ACS Appl Mater Interfaces 7:1516-1526. https://doi.org/10.1021/am506568v

36. Krismastuti FSH, Bayat H, Voelcker NH, Schönherr H (2015) Real time monitoring of layer-by-layer polyelectrolyte deposition and bacterial enzyme detection in nanoporous anodized aluminum oxide. Anal Chem 87:3856-3863. https://doi.org/10.1021/ ac504626m

37. Wang J, Pan S (2017) Electrodeposition of vertically standing Ag nanoplates and nanowires on transparent conductive electrode using porous anodic aluminum oxide template. Nanotechnology 28:425601. https://doi.org/10.1088/1361-6528/aa8614

38. Winkler R, Tu W, Laskowski L, Adrjanowicz K (2020) Effect of surface chemistry on the glass-transition dynamics of poly(phenyl methyl siloxane) confined in alumina nanopores. Langmuir 36: 7553-7565. https://doi.org/10.1021/acs.langmuir.0c01194

39. Liu C-T, Lin Y-L, Chu C-W, Chang CW, Chiu YJ, Chiu TY, Lee LR, Chen JT (2019) Asymmetries in porous membranes: fabrication of anodic aluminum oxide membranes with double-sized nanopores and controlled surface properties. J Phys Chem C 123:14540-14546. https://doi.org/10.1021/acs.jpcc.9b03079

40. Kwak SH, Kwon S-R, Baek S, Lim SM, Joo YC, Chung TD (2016) Densely charged polyelectrolyte-stuffed nanochannel arrays for power generation from salinity gradient. Sci Rep 6: 26416. https://doi.org/10.1038/srep26416

41. Pol L, Acosta LK, Ferré-Borrull J, Marsal LF (2019) Aptamerbased nanoporous anodic alumina interferometric biosensor for real-time thrombin detection. Sensors 19:4543. https://doi.org/ 10.3390/s19204543

42. Haider A, Deminskyi P, Yilmaz M, Elmabruk K, Yilmaz I, Biyikli N (2018) Long-range ordered vertical III-nitride nano-cylinder arrays via plasma-assisted atomic layer deposition. J Mater Chem C 6:6471-6482. https://doi.org/10.1039/C8TC01165F

43. Cho GY, Noh S, Lee YH et al (2016) Properties of nanostructured undoped $\mathrm{ZrO} 2$ thin film electrolytes by plasma enhanced atomic layer deposition for thin film solid oxide fuel cells. J Vac Sci Technol A Vacuum, Surfaces, Film 34:01A151. https://doi.org/ $10.1116 / 1.4938105$

44. Zhan H, Garrett DJ, Apollo NV, Ganesan K, Lau D, Prawer S, Cervenka J (2016) Direct fabrication of 3D graphene on nanoporous anodic alumina by plasma-enhanced chemical vapor deposition. Sci Rep 6:19822. https://doi.org/10.1038/srep19822

45. Ji S, Cho GY, Yu W, Su PC, Lee MH, Cha SW (2015) Plasmaenhanced atomic layer deposition of nanoscale yttria-stabilized zirconia electrolyte for solid oxide fuel cells with porous substrate. ACS Appl Mater Interfaces 7:2998-3002. https://doi.org/10.1021/ am508710s

46. Lee K, Kim H, Kim JH, Choi D (2020) Structural color and nearinfrared tunability of ruthenium-coated anodic aluminum oxide by atomic layer deposition. Scr Mater 187:125-129. https://doi.org/ 10.1016/j.scriptamat.2020.06.007

47. Chat K, Tu W, Beena Unni A, Geppert-Rybczyńska M, Adrjanowicz K (2020) Study on the glass transition dynamics and crystallization kinetics of molecular liquid, dimethyl phthalate, confined in anodized aluminum oxide (AAO) nanopores with atomic layer deposition (ALD) coatings. J Mol Liq 311:113296. https://doi.org/10.1016/j.molliq.2020.113296

48. Fang Z-X, Chu C-W, Tsai C-C, Chang CW, Cheng MH, Chang CC, Chen JT (2020) Rayleigh-instability-induced transformation for confined polystyrene nanotubes prepared using the solvent- 
vapor-induced wetting method. Macromol Mater Eng 305: 1900465. https://doi.org/10.1002/mame.201900465

49. Huang Y, Sarkar D, Chen X-G (2016) Fabrication of corrosion resistance micro-nanostructured superhydrophobic anodized aluminum in a one-step electrodeposition process. Metals (Basel) 6: 47. https://doi.org/10.3390/met6030047

50. Nehra M, Dilbaghi AN, Singh V, Singhal NK, Kumar S (2020) Highly ordered and crystalline $\mathrm{Cu}$ nanowires in anodic aluminum oxide membranes for biomedical applications. Phys Status Solidi 217:1900842. https://doi.org/10.1002/pssa.201900842

51. Mebed AM, Abd-Elnaiem AM, Al-Hosiny NM (2016) Electrochemical fabrication of 2D and 3D nickel nanowires using porous anodic alumina templates. Appl Phys A Mater Sci Process 122:565. https://doi.org/10.1109/TMAG.2019.2942946

52. Ercole F, Davis TP, Evans RA (2010) Photo-responsive systems and biomaterials: photochromic polymers, light-triggered self-assembly, surface modification, fluorescence modulation and beyond. Polym Chem 1:37-54. https://doi.org/10.1039/ B9PY00300B

53. Ulman A (1996) Formation and structure of self-assembled monolayers. Chem Rev 96:1533-1554. https://doi.org/10.1021/ cr9502357

54. Pujari SP, Scheres L, Marcelis ATM, Zuilhof H (2014) Covalent surface modification of oxide surfaces. Angew Chem Int Ed 53: 6322-6356. https://doi.org/10.1002/anie.201306709

55. Szczepanski V, Vlassiouk I, Smirnov S (2006) Stability of silane modifiers on alumina nanoporous membranes. J Membr Sci 281: 587-591. https://doi.org/10.1016/j.memsci.2006.04.027

56. Mutalib Jani A, Anglin EJ, McInnes SJP et al (2009) Nanoporous anodic aluminium oxide membranes with layered surface chemistry. Chem Commun 21:3062-3064. https://doi.org/10.1039/ b901745c

57. Jani AMM, Kempson IM, Losic D, Voelcker NH (2010) Dressing in layers: layering surface functionalities in nanoporous aluminum oxide membranes. Angew Chem Int Ed 49:7933-7937. https:// doi.org/10.1002/anie.201002504

58. Pathak A, Bora A, Braunschweig B, Meltzer C, Yan H, Lemmens P, Daum W, Schwartz J, Tornow M (2017) Nanocylindrical confinement imparts highest structural order in molecular selfassembly of organophosphonates on aluminum oxide. Nanoscale 9:6291-6295. https://doi.org/10.1039/c7nr02420g

59. Bauer T, Schmaltz T, Lenz T, Halik M, Meyer B, Clark T (2013) Phosphonate- and carboxylate-based self-assembled monolayers for organic devices: a theoretical study of surface binding on aluminum oxide with experimental support. ACS Appl Mater Interfaces 5:6073-6080. https://doi.org/10.1021/am4008374

60. Kim SY, Lee MY, Lee JY, Park YH, Kim HG, Jeong CJ, Mosaiab T, Park B, Park SY, in I (2013) Mussel-inspired engineering of an anodized aluminum oxide membrane. Chem Lett 42:902-903. https://doi.org/10.1246/cl.130269

61. ter Maat J, Regeling R, Ingham CJ et al (2011) Organic modification and subsequent biofunctionalization of porous anodic alumina using terminal alkynes. Langmuir 27:13606-13617. https:// doi.org/10.1021/la203738h

62. Costa RR, Mano JF (2013) Layer-by-layer self-assembly techniques for nanostructured devices in tissue engineering. In: Nanomaterials in tissue engineering. Elsevier, pp 88-118

63. Peyratout CS, Dähne L (2004) Tailor-made polyelectrolyte microcapsules: from multilayers to smart containers. Angew Chem Int Ed 43:3762-3783. https://doi.org/10.1002/anie.200300568

64. Ai S, Lu G, He Q, Li J (2003) Highly flexible polyelectrolyte nanotubes. J Am Chem Soc 125:11140-11141. https://doi.org/ $10.1021 / \mathrm{ja} 0356378$

65. Roy D, Semsarilar M, Guthrie JT, Perrier S (2009) Cellulose modification by polymer grafting: a review. Chem Soc Rev 38: 2046-2064. https://doi.org/10.1039/b808639g
66. Shang J, Lin S, Theato P (2017) Fabrication of color changeable CO 2 sensitive nanofibers. Polym Chem 8:7446-7451. https://doi. org/10.1039/C7PY01628J

67. Chen F, Jiang X, Kuang T, Chang L, Fu D, Yang Z, Yang J, Fan P, Fei Z, Zhong M (2015) Effect of nanoporous structure and polymer brushes on the ionic conductivity of poly(methacrylic acid)/ anode aluminum oxide hybrid membranes. RSC Adv 5:70204 70210. https://doi.org/10.1039/C5RA08990E

68. Li P-F, Xie R, Jiang J-C, Meng T, Yang M, Ju XJ, Yang L, Chu LY (2009) Thermo-responsive gating membranes with controllable length and density of poly( $\mathrm{N}$-isopropylacrylamide) chains grafted by ATRP method. J Membr Sci 337:310-317. https:// doi.org/10.1016/j.memsci.2009.04.010

69. Jang JH, In I (2010) Poly(N-isopropylacrylamide)-grafted thermosensitive anodized aluminum oxide membrane. Chem Lett 39:1190-1191. https://doi.org/10.1246/cl.2010.1190

70. Yang Z, Peng H, Wang W, Liu T (2010) Crystallization behavior of poly( $\varepsilon$-caprolactone)/layered double hydroxide nanocomposites. J Appl Polym Sci 116:2658-2667. https://doi.org/10.1002/ app

71. Nouri A, Wen C (2015) Introduction to surface coating and modification for metallic biomaterials. In: Surface coating and modification of metallic biomaterials. Elsevier, pp 3-60

72. Fan HJ, Werner P, Zacharias M (2006) Semiconductor nanowires: from self-organization to patterned growth. Small 2:700-717. https://doi.org/10.1002/smll.200500495

73. Ding D, Cai W, Long M, Wu H, Wu Y (2010) Optical, structural and thermal characteristics of $\mathrm{CuCuAl} 2 \mathrm{O} 4$ hybrids deposited in anodic aluminum oxide as selective solar absorber. Sol Energy Mater Sol Cells 94:1578-1581. https://doi.org/10.1016/j.solmat. 2010.04.075

74. Zhang Q, Liu Z, Wang K, Zhai J (2015) Organic/inorganic hybrid nanochannels based on polypyrrole-embedded alumina nanopore arrays: $\mathrm{Ph}$-and light-modulated ion transport. Adv Funct Mater 25: 2091-2098. https://doi.org/10.1002/adfm.201404160

75. Duay J, Gillette E, Hu J, Lee SB (2013) Controlled electrochemical deposition and transformation of hetero-nanoarchitectured electrodes for energy storage. Phys Chem Chem Phys 15:79767993. https://doi.org/10.1039/c3cp50724f

76. Brzózka A, Fic K, Bogusz J, Brudzisz A, Marzec M, Gajewska M, Sulka G (2019) Polypyrrole-nickel hydroxide hybrid nanowires as future materials for energy storage. Nanomaterials 9:307. https://doi.org/10.3390/nano9020307

77. Lahav M, Weiss EA, Xu Q, Whitesides GM (2006) Core-Shell and segmented polymer-metal composite nanostructures. Nano Lett 6:2166-2171. https://doi.org/10.1021/nl061786n

78. Wen L, Wang Z, Mi Y, Xu R, Yu SH, Lei Y (2015) Designing heterogeneous 1D nanostructure arrays based on AAO templates for energy applications. Small 11:3408-3428. https://doi.org/10. 1002/smll.201500120

79. Djokić SS, Cavallotti PL (2010) Electroless deposition: theory and applications. In: Electrodeposition. Springer, pp 251-289

80. Sha W, Wu X, Keong KG (2011) Electroless copper and nickelphosphorus plating: processing, characterisation and modelling. Elsevier

81. Linga Reddy E, Lee HC, Kim DH (2015) Steam reforming of methanol over structured catalysts prepared by electroless deposition of $\mathrm{Cu}$ and $\mathrm{Zn}$ on anodically oxidized alumina. Int J Hydrog Energy 40:2509-2517. https://doi.org/10.1016/j.ijhydene.2014. 12.094

82. Chen N, Kim DH, Kovacik P, Sojoudi H, Wang M, Gleason KK (2016) Polymer thin films and surface modification by chemical vapor deposition: recent progress. Annu Rev Chem Biomol Eng 7: 373-393. https://doi.org/10.1146/annurev-chembioeng-080615033524 
83. Zhao C, Li Q, Wan W, Li J, Li J, Zhou H, Xu D (2012) Coaxial carbon-silicon-carbon nanotube arrays in porous anodic aluminum oxide templates as anodes for lithium ion batteries. J Mater Chem 22:12193-12197. https://doi.org/10.1039/c2jm31162c

84. Yang R, Asatekin A, Gleason KK (2012) Design of conformal, substrate-independent surface modification for controlled proteinadsorption by chemical vapor deposition (CVD). Soft Matter 8:31-43. https://doi.org/10.1039/C1SM06334K

85. Tufani A, Ince GO (2015) Permeability of small molecules through vapor deposited polymer membranes. J Appl Polym Sci 132:1-7. https://doi.org/10.1002/app.42453

86. Armagan E, Ozaydin Ince G (2015) Coaxial nanotubes of stimuli responsive polymers with tunable release kinetics. Soft Matter 11: 8069-8075. https://doi.org/10.1039/C5SM01074H

87. Tenhaeff WE, Gleason KK (2008) Initiated and Oxidative chemical vapor deposition of polymeric thin films: iCVD and oCVD. Adv Funct Mater 18:979-992. https://doi.org/10.1002/adfm. 200701479

88. Losic D, Cole MA, Dollmann B, Vasilev K, Griesser HJ (2008) Surface modification of nanoporous alumina membranes by plasma polymerization. Nanotechnology 19:245704. https://doi.org/ 10.1088/0957-4484/19/24/245704

89. Tufani A, Ozaydin Ince G (2017) Smart membranes with pHresponsive control of macromolecule permeability. J Membr Sci 537:255-262. https://doi.org/10.1016/j.memsci.2017.05.024

90. George SM (2010) Atomic layer deposition: an overview. Chem Rev 110:111-131. https://doi.org/10.1021/cr900056b

91. Velleman L, Triani G, Evans PJ, Shapter JG, Losic D (2009) Structural and chemical modification of porous alumina membranes. Microporous Mesoporous Mater 126:87-94. https://doi. org/10.1016/j.micromeso.2009.05.024

92. Al-Kaysi RO, Ghaddar TH, Guirado G (2009) Fabrication of onedimensional organic nanostructures using anodic aluminum oxide templates. J Nanomater 2009:1-14. https://doi.org/10.1155/2009/ 436375

93. Kim J-U, Haberkorn N, Theato P, Zentel R (2011) Controlled fabrication of organic nanotubes via self-assembly of nonsymmetric bis-acylurea. Colloid Polym Sci 289:1855-1862. https://doi.org/10.1007/s00396-011-2512-y

94. Cannon JP, Bearden SD, Gold SA (2010) Characterization of conjugated polymer/anodic aluminum oxide nanocomposites fabricated via template wetting. Compos Part A Appl Sci Manuf 41: 836-841. https://doi.org/10.1016/j.compositesa.2010.02.014

95. Dong X, Tong F, Hanson KM, al-Kaysi RO, Kitagawa D, Kobatake S, Bardeen CJ (2019) Hybrid Organic-inorganic photon-powered actuators based on aligned diarylethene nanocrystals. Chem Mater 31:1016-1022. https://doi.org/10. 1021/acs.chemmater.8b04568

96. Wu D, Zhang D, Ye Y, Ma L, Minhas B, Liu B, Terryn HA, Mol JMC, Li X (2019) Durable lubricant-infused anodic aluminum oxide surfaces with high-aspect-ratio nanochannels. Chem Eng J 368:138-147. https://doi.org/10.1016/j.cej.2019.02.163

97. Chen Z, Chen T, Sun X, Hinds BJ (2014) Dynamic electrochemical membranes for continuous affinity protein separation. Adv Funct Mater 24:4317-4323. https://doi.org/10.1002/adfm. 201303707

98. Lee B, Hyun S, Jeon G, Kim EY, Kim J, Kim WJ, Kim JK (2016) Bioinspired dual stimuli-responsive membranous system with multiple on-off gates. ACS Appl Mater Interfaces 8:1175811764. https://doi.org/10.1021/acsami.6b01788

99. Tufani A, Ozaydin Ince G (2019) Protein gating by vapor deposited Janus membranes. J Membr Sci 575:126-134. https://doi.org/ 10.1016/j.memsci.2019.01.013

100. Shi W, Shen Y, Jiang H, Song C, Ma Y, Mu J, Yang B, Ge D (2010) Lysine-attached anodic aluminum oxide (AAO)-silica affinity membrane for bilirubin removal. J Membr Sci 349:333340. https://doi.org/10.1016/j.memsci.2009.11.066

101. Osmanbeyoglu HU, Hur TB, Kim HK (2009) Thin alumina nanoporous membranes for similar size biomolecule separation. J Membr Sci 343:1-6. https://doi.org/10.1016/j.memsci.2009.07. 027

102. Liu K, Huang Z, Hemmatifar A, Oyarzun DI, Zhou J, Santiago JG (2018) Self-cleaning porous surfaces for dry condensation. ACS Appl Mater Interfaces 10:26759-26764. https://doi.org/10.1021/ acsami.8b07261

103. Jo H, Haberkorn N, Pan J-A, Vakili M, Nielsch K, Theato P (2016) Fabrication of chemically tunable, hierarchically branched polymeric nanostructures by multi-branched anodic aluminum oxide templates. Langmuir 32:6437-6444. https://doi.org/10.1021/ acs.langmuir.6b00163

104. Uchida K, Fujita M, Aoi Y, Saito M, Irie M (2001) Photochromism of diarylethenes on porous aluminum oxide: fatigue resistance and redox potentials of the photochromes. Chem Lett 30:366-367. https://doi.org/10.1246/cl.2001.366

105. Liu, Dunphy DR, Atanassov P et al (2004) Photoregulation of mass transport through a photoresponsive azobenzene-modified nanoporous membrane. Nano Lett 4:551-554. https://doi.org/10. $1021 / \mathrm{n} 10350783$

106. Fujiwara M, Imura T (2015) Photo induced membrane separation for water purification and desalination using azobenzene modified anodized alumina membranes. ACS Nano 9:5705-5712. https:// doi.org/10.1021/nn505970n

107. Song J, Oh H, Kong H, Jang J (2011) Polyrhodanine modified anodic aluminum oxide membrane for heavy metal ions removal. J Hazard Mater 187:311-317. https://doi.org/10.1016/j.jhazmat. 2011.01.026

108. Kantipuly C, Katragadda S, Chow A, Gwsser H (1990) Chelating polymers and related supports for separation and preconcentration of trace metals. Talanta 37:491-517. https://doi.org/10.1016/ 0039-9140(90)80075-Q

109. Phuong NT, Andisetiawan A, Van Lam D et al (2016) Nano sand filter with functionalized nanoparticles embedded in anodic aluminum oxide templates. Sci Rep 6:1-8. https://doi.org/10.1038/ srep37673

110. Petukhov DI, Chernova EA, Kapitanova OO, Boytsova OV, Valeev RG, Chumakov AP, Konovalov OV, Eliseev AA (2019) Thin graphene oxide membranes for gas dehumidification. J Membr Sci 577:184-194. https://doi.org/10.1016/j.memsci. 2019.01.041

111. Stair PC, Marshall C, Xiong G, Feng H, Pellin MJ, Elam JW, Curtiss L, Iton L, Kung H, Kung M, Wang HH (2006) Novel, uniform nanostructured catalytic membranes. Top Catal 39:181186. https://doi.org/10.1007/s11244-006-0055-0

112. Yu Y, Wu X-J, Zhao M, Ma Q, Chen J, Chen B, Sindoro M, Yang J, Han S, Lu Q, Zhang H (2017) Anodized aluminum oxide templated synthesis of metal-organic frameworks used as membrane reactors. Angew Chem 129:593-596. https://doi.org/10.1002/ ange. 201610291

113. Lu S, An Z, He J, Li B (2012) Hierarchically-structured immobilized enzyme displaying the multi-functions of bio-membranes. J Mater Chem 22:3882-3888. https://doi.org/10.1039/ c2jm14602a

114. Hussain MA, Irshad M, Haq EU, Park S, Atif M, Hakeem AS, Choi BG, Kim JW (2019) Porous anodic aluminum oxide as an efficient support for ruthenium-catalyzed aerobic oxidation of alcohols and amines. Ind Eng Chem Res 58:23025-23031. https:// doi.org/10.1021/acs.iecr.9b06054

115. Zhou L, Tan Y, Ji D, Zhu B, Zhang P, Xu J, Gan Q, Yu Z, Zhu J (2016) Self-assembly of highly efficient, broadband plasmonic absorbers for solar steam generation. Sci Adv 2:e1501227. https://oi.org/10.1126/sciadv.1501227 
116. Kwon CW, Son JW, Lee JH, Kim HM, Lee HW, Kim KB (2011) High-performance micro-solid oxide fuel cells fabricated on nanoporous anodic aluminum oxide templates. Adv Funct Mater 21:1154-1159. https://doi.org/10.1002/adfm.201002137

117. Chen J, Wang S, Ding L, Jiang Y, Wang H (2014) Performance of through-hole anodic aluminum oxide membrane as a separator for lithium-ion battery. J Membr Sci 461:22-27. https://doi.org/10. 1016/j.memsci.2014.03.005

118. Ali HO (2017) Review of porous anodic aluminium oxide (AAO) applications for sensors, MEMS and biomedical devices. Trans Inst Met Finish 95:290-296. https://doi.org/10.1080/00202967. 2017.1358514

119. Chen W, Gui X, Liang B, Yang R, Zheng Y, Zhao C, Li X, Zhu H, Tang Z (2017) Structural engineering for high sensitivity, ultrathin pressure sensors based on wrinkled graphene and anodic aluminum oxide membrane. ACS Appl Mater Interfaces 9:2411124117. https://doi.org/10.1021/acsami.7b05515

120. Ma Y, Kaczynski J, Ranacher C, Roshanghias A, Zauner M, Abasahl B (2018) Nano-porous aluminum oxide membrane as filtration interface for optical gas sensor packaging. Microelectron Eng 198:29-34. https://doi.org/10.1016/j.mee. 2018.06.013

121. Amouzadeh Tabrizi M, Ferré-Borrull J, Marsal LF (2020) Highly sensitive remote biosensor for the determination of lead (II) ions by using nanoporous anodic alumina modified with DNAzyme. Sensors Actuators B Chem 321:128314. https://doi.org/10.1016/j. snb.2020.128314

122. Xin W, Zhang Z, Huang X, Hu Y, Zhou T, Zhu C, Kong XY, Jiang L, Wen L (2019) High-performance silk-based hybrid membranes employed for osmotic energy conversion. Nat Commun 10:3876. https://doi.org/10.1038/s41467-019-11792-8

123. Kim S, Hyun S, Lee J, Lee KS, Lee W, Kim JK (2018) Anodized aluminum oxide/polydimethylsiloxane hybrid mold for roll-to-roll nanoimprinting. Adv Funct Mater 28:1800197. https://doi.org/10. 1002/adfm.201800197

124. Murphy MP, Kim S, Sitti M (2009) Enhanced Adhesion by gecko-inspired hierarchical fibrillar adhesives. ACS Appl Mater Interfaces 1:849-855. https://doi.org/10.1021/am8002439

125. Carbone G, Pierro E, Gorb SN (2011) Origin of the superior adhesive performance of mushroom-shaped microstructured surfaces. Soft Matter 7:5545. https://doi.org/10.1039/c0sm01482f

126. Arzt E, Gorb S, Spolenak R (2003) From micro to nano contacts in biological attachment devices. Proc Natl Acad Sci 100:1060310606. https://doi.org/10.1073/pnas.1534701100

127. Greiner C, del Campo A, Arzt E (2007) Adhesion of bioinspired micropatterned surfaces: effects of pillar radius, aspect ratio, and preload. Langmuir 23:3495-3502. https://doi.org/10.1021/ la0633987

128. del Campo A, Greiner C, Álvarez I, Arzt E (2007) Patterned surfaces with pillars with controlled 3D tip geometry mimicking bioattachment devices. Adv Mater 19:1973-1977. https://doi. org/10.1002/adma.200602476
129. Zhang R, Zhang L, Tian N, Ma S, Liu Y, Yu B, Pei X, Zhou F (2017) The Tethered fibrillar hydrogels brushes for underwater antifouling. Adv Mater Interfaces 4. https://doi.org/10.1002/ admi.201601039

130. Du T, Ma S, Pei X et al (2017) Bio-inspired design and fabrication of micro/nano-brush dual structural surfaces for switchable oil adhesion and antifouling. Small 13:1602020. https://doi.org/10. 1002/smll.201602020

131. Ma S, Scaraggi M, Lin P, Yu B, Wang D, Dini D, Zhou F (2017) Nanohydrogel brushes for switchable underwater adhesion. J Phys Chem C 121:8452-8463. https://doi.org/10.1021/acs.jpcc. $7 \mathrm{~b} 01305$

132. Kwak D-H, Yoo J-B, Kim DJ (2010) Drug release behavior from nanoporous anodic aluminum oxide. J Nanosci Nanotechnol 10: 345-348. https://doi.org/10.1166/jnn.2010.1531

133. Szuwarzyński M, Zaraska L, Sulka GD, Zapotoczny S (2013) Pulsatile releasing platform of nanocontainers equipped with thermally responsive polymeric nanovalves. Chem Mater 25:514 520. https://doi.org/10.1021/cm303930y

134. Hong C, Tang TT, Hung CY, Pan RP, Fang W (2010) Liquid crystal alignment in nanoporous anodic aluminum oxide layer for LCD panel applications. Nanotechnology 21:285201. https:// doi.org/10.1088/0957-4484/21/28/285201

135. Yilmaz B, Yüksel B, Orhan G, Aydin D, Utlu Z (2020) Synthesis and characterization of salt-impregnated anodic aluminum oxide composites for low-grade heat storage. Int J Miner Metall Mater 27:112-118. https://doi.org/10.1007/s12613-019-1890-x

136. Liu Y, Wang HH, Indacochea JE, Wang ML (2011) A colorimetric sensor based on anodized aluminum oxide (AAO) substrate for the detection of nitroaromatics. Sensors Actuators B Chem 160: 1149-1158. https://doi.org/10.1016/j.snb.2011.09.040

137. Kim D-K, Kerman K, Hiep HM, Saito M, Yamamura S, Takamura Y, Kwon YS, Tamiya E (2008) Label-free optical detection of aptamer-protein interactions using gold-capped oxide nanostructures. Anal Biochem 379:1-7. https://doi.org/10.1016/j. ab.2008.04.029

138. Xu Z, Wan L, Huang X (2009) Functionalization methods for membrane surfaces. In: Surface engineering of polymer membranes. Springer, pp 64-79

139. Hou S, Harrell CC, Trofin L, Kohli P, Martin CR (2004) Layerby-layer nanotube template synthesis. J Am Chem Soc 126:56745675. https://doi.org/10.1021/ja049537t

140. Zhao H, Liu L, Lei Y (2018) A mini review: functional nanostructuring with perfectly-ordered anodic aluminum oxide template for energy conversion and storage. Front Chem Sci Eng 12:481-493. https://doi.org/10.1007/s11705-018-1707-x

Publisher's note Springer Nature remains neutral with regard to jurisdictional claims in published maps and institutional affiliations. 